\title{
Role of ligands in controlling the regioselectivity in ruthenium-catalysed addition of carboxylic acids to terminal alkynes: A DFT study
}

\author{
BHOLANATH MAITY, TOTAN MONDAL, KAUSTAV DEY, SANKARSAN BISWAS \\ and DEBASIS KOLEY* \\ Department of Chemical Sciences, Indian Institute of Science Education and Research (IISER) Kolkata, \\ Mohanpur 741 246, India \\ e-mail: koley@iiserkol.ac.in
}

MS received 13 August 2014; accepted 12 September 2014

\begin{abstract}
Density functional studies are performed to understand the role of chelating $b i$-phosphine ligands $\left[\left(\mathrm{Ph}_{2} \mathrm{P}\left(\mathrm{CH}_{2}\right)_{m} \mathrm{PPh}_{2}\right) ; m=1-4\right]$ in modulating the regio-selectivity of benzoic acid addition to 1-hexyne, in presence of ruthenium(II) catalyst $\left[\left(\mathrm{Ph}_{2} \mathrm{P}\left(\mathrm{CH}_{2}\right)_{\mathrm{m}} \mathrm{PPh}_{2}\right) \mathrm{Ru}(\text { methallyl })_{2}\right]$. The Markovnikov addition to 1-hexyne is observed when catalyst $\mathbf{1}_{\mathbf{a}}\left[\left(\mathrm{Ph}_{2} \mathrm{P}\left(\mathrm{CH}_{2}\right) \mathrm{PPh}_{2}\right) \mathrm{Ru}(\text { methallyl })_{2}\right]$ is employed, whereas a reverse regio-selectivity is witnessed in presence of $\mathbf{1}_{\mathbf{d}}\left[\left(\mathrm{Ph}_{2} \mathrm{P}\left(\mathrm{CH}_{2}\right)_{4} \mathrm{PPh}_{2}\right) \mathrm{Ru}(\text { methallyl })_{2}\right]$. Anti-Markovnikov addition occurs via the neutral vinylidene intermediates $\left(\mathbf{5}_{\mathbf{a} / \mathbf{d}}\right)$ formed after 1,2-hydrogen shift in hexyne coordinated ruthenium(II) complexes $\mathbf{3}_{\mathrm{a} / \mathbf{d}}$. The energy profile shows clear preference for Markovnikov addition by $15.0 \mathrm{kcal} / \mathrm{mol}\left(\Delta G_{\mathrm{L}}^{S}\right)$ in case of catalyst system $\mathbf{1}_{\mathbf{a}}$. In contrast, anti-Markovnikov pathway following neutral vinylidenes are more favourable by $9.1 \mathrm{kcal} / \mathrm{mol}\left(\Delta G_{\mathrm{L}}^{S}\right)$ for catalyst system $\mathbf{1}_{\mathbf{d}}$. The $Z$-enol ester formation is more predominant in the anti-Markovnikov pathway since the activation barrier for this step requires less energy $(5.9 \mathrm{kcal} / \mathrm{mol}$, $\Delta G_{\mathrm{L}}^{S}$ ) than the one furnishing the $E$-product. The calculated results are in good agreement with the reported experimental findings.
\end{abstract}

Keywords. Enol esters; DFT; regio-selectivity; ligands; ruthenium(II) catalyst.

\section{Introduction}

Enol esters are useful precursors in organic synthesis, especially for the regio- and stereo-selective generation of enolates. ${ }^{1}$ They have been used as intermediates in carbon-carbon and carbon-heteroatom bond formation and also act as versatile substrates for a variety of well-known organic transformations. Furthermore, vinyl esters such as vinyl acetates and acetoxystyrenes are important precursors for the preparation of various polymers and copolymers. ${ }^{2}$ The most efficient method for the preparation of these compounds is the ruthenium-catalysed addition of carboxylic acids to alkynes. For the first time, Rotem and Shvo used ruthenium metal catalyst such as $\mathrm{Ru}_{3}(\mathrm{CO})_{12}$ and $\left[\mathrm{Ru}(\mathrm{CO})_{2}\left(\mathrm{O}_{2} \mathrm{CCH}_{3}\right)\right]_{\mathrm{n}}$ for the addition of carboxylic acids to substituted acetylenes under harsh conditions, resulting mainly in the regio-selective Markovnikov products. $^{3}$ The reaction was further developed by the groups of Mitsudo and Dixneuf, with the introduction of more active catalysts, for e.g., bis(cyclooctadienyl)Ru-phosphine-maleic anhydride or $\operatorname{Ru}\left(\eta^{3} \text {-methallyl }\right)_{2}$-phosphine combinations. ${ }^{4,5}$

*For correspondence
Later, Bruneau et al. reported the catalytic activation of valuable $\mathrm{C} 3$-feedstock viz. propadiene and propyne, towards the addition of carboxylic acids in presence of binuclear ruthenium catalyst to form isopropenyl esters, subsequently enhancing the industrial importance of this transformation. ${ }^{6}$ To increase the efficiency and versatility of this method, Gooßen et al. synthesized a new catalyst system that can furnish both Markovnikov and anti-Markovnikov regio-products in excellent selectivity. ${ }^{7}$

Interestingly, Doucet and Dixneuf have reported that with the modification of the chelating bidentate ligands, the regio-selectivity of the nucleophilic addition can be controlled allowing predominant formation of a given hexenyl benzoate isomer (I, II, III; scheme 1). To be precise, experimental observations reveal that catalytic systems $\mathbf{1}_{\mathbf{a}}$ and $\mathbf{1}_{\mathbf{d}}$, differing only in their spacer groups ( $m=1$ in $\mathbf{1}_{\mathbf{a}}$ vs. 4 in $\mathbf{1}_{\mathbf{d}}$ ) are capable of reversing the regio-selectivity with predominant formation of the Markovnikov addition product $\mathbf{I}$ in the former case and anti-Markovnikov enol ester II in the latter (scheme 1). The same authors proposed a mechanistic route to explain the regioselectivity for the alkyne coupling with carboxylic acid as depicted in scheme $2 .^{5}$ 


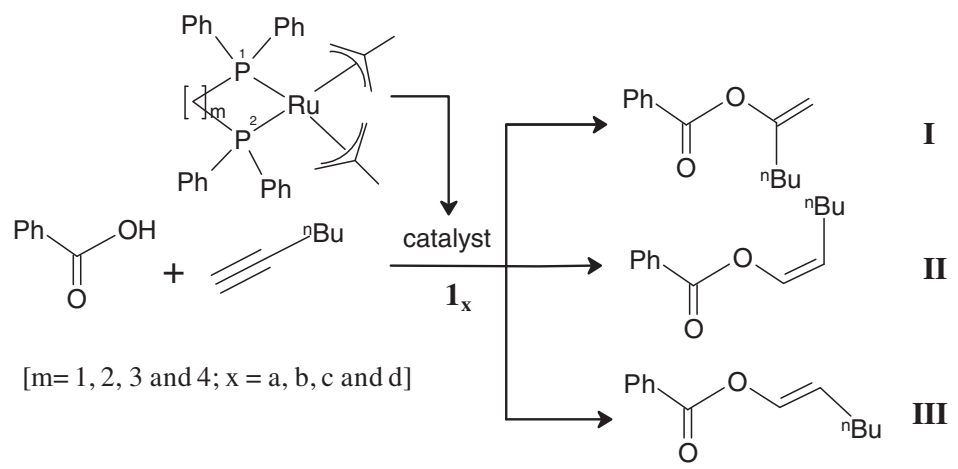

Scheme 1. Enol ester formation via carboxylic acid addition to alkynes in presence of ruthenium catalyst.

It was suggested that the initial step of the catalytic reaction involves a facile ligand exchange by the active catalyst $\mathbf{1}_{\mathbf{x}}$ to form the ruthenium carboxylate species $\mathbf{2}_{\mathbf{x}}$ (scheme 3$)$. A rearrangement from $\left(\eta^{2}\right.$-carboxylate) to ( $\eta^{1}$-catboxylate) species $\mathbf{3}_{\mathbf{x}}$ will provide room for the coordination of the incoming alkyne moiety. Subsequent hexyne coordination will furnish intermediate 3 , which can equilibrate in several of its resonance forms $\left(\mathbf{3}_{-} \mathbf{i}_{\mathbf{x}}\right.$ and $\mathbf{3} \mathbf{i}_{\mathbf{x}}$, scheme 2), including the vinylidene isomer $\mathbf{5}_{\mathbf{x}}$. In organometallic catalysis, metal vinylidenes are the commonly preferred ligands in both mono- and polynuclear metal complexes. ${ }^{8}$ Carboxylate will attack

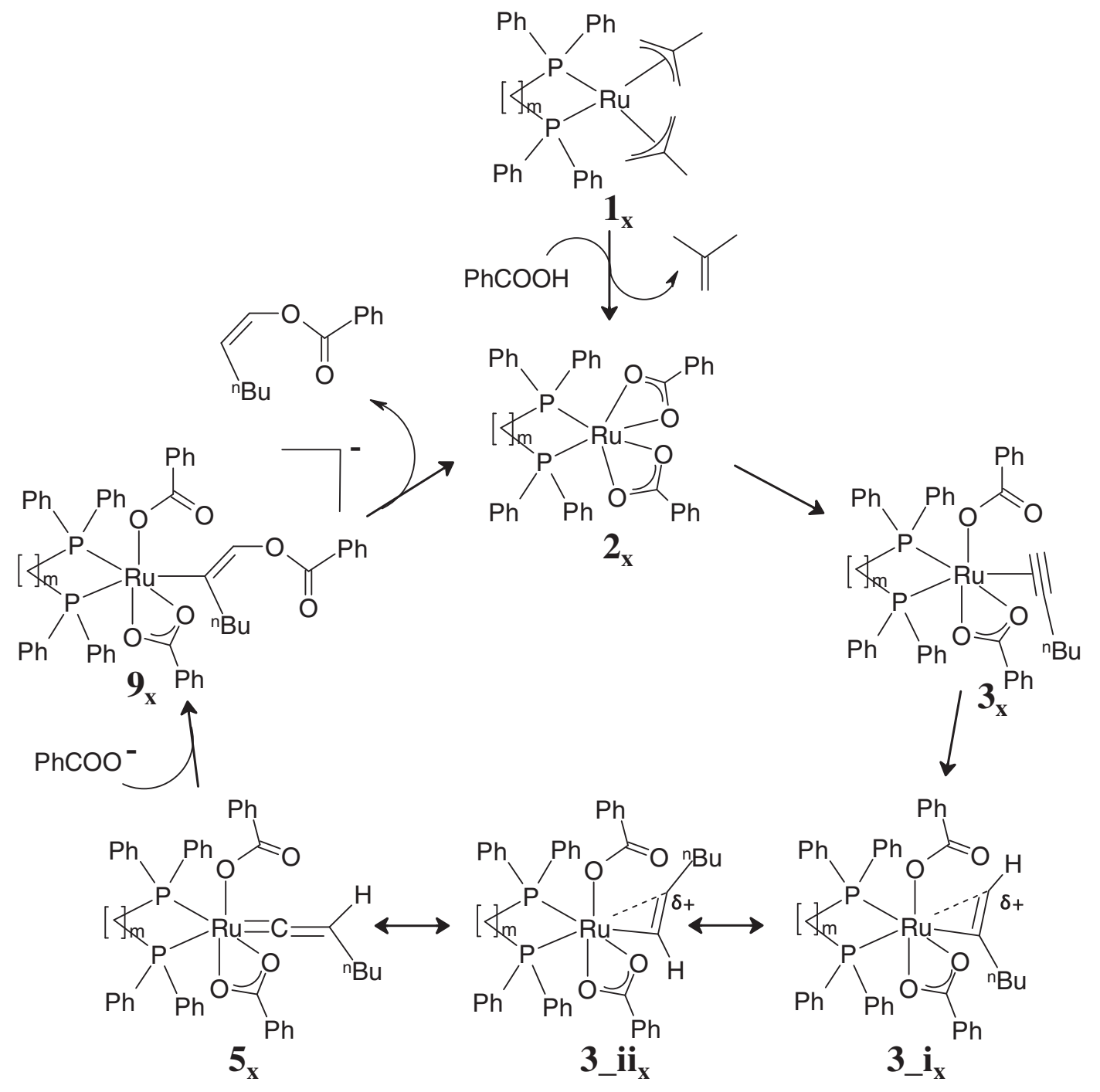

Scheme 2. Probable mechanistic scheme for the addition of carboxylic acids to alkynes as proposed by Dixneuf $e t$ al. $^{5 \mathrm{~b}}$ 
the electrophilic carbon of the coordinated alkyne moiety to form intermediate $\mathbf{9}_{\mathbf{x}}$. Subsequent protonolysis of the ruthenium-carbon bond, or protonation of the ruthenium centre followed by reductive elimination, will liberate the desired enol ester product as sketched in scheme 1. It is pertinent that the regioselectivity may depend on the electronic environment of the coordinated alkyne species. The carboxylate addition will take place at the most electrophilic carbon atom of the terminal alkyne, the electronic effect of which is unambiguously influenced by the chelating diphosphine ligand. Alternatively the addition can occur at the $\mathrm{C}_{\alpha}$ of the vinylidene species $\mathbf{5}_{\mathbf{x}}$ to afford the anti-Markovnikov products II and III.

In this study, we investigate both the existence as well as relative stabilities of the intermediates proposed in the catalytic cycle using computational methodology. Furthermore, we will address the role of the chelating ligands in modulating the electronic environment on the metal centre, which in turn influences the charge distribution of the coordinated hexyne fragment. The energetics of the fundamental steps including the nucleophilic attack will be analysed for two sets of catalyst systems $\mathbf{1}_{\mathbf{a}}$ and $\mathbf{1}_{\mathbf{d}}$. On the basis of the energy difference, the preference for a given pathway leading to particular enol esters will be discussed.

\section{Computational Details}

All calculations were performed using Gaussian09 ${ }^{9}$ program packages. The geometries of stationary points and transition states were optimized using the two-layer
ONIOM(MO:MO $)^{10}$ method. The ONIOM high level has been designated for the whole molecules except phenyl ring $(-\mathrm{Ph})$ in phosphine ligands and treated with meta hybrid generalized gradient approximation ( $m$-GGA) by means of M06-2X functional employing basis set with the relativistic effective core potential of Hay and Wadt (LANL2DZ) ${ }^{11}$ for ruthenium atom and $6-31 \mathrm{G}(\mathrm{d})^{12}$ for other elements $(\mathrm{H}, \mathrm{C}, \mathrm{N} \mathrm{O}$ and $\mathrm{P})$. The ONIOM low level $(-\mathrm{Ph})$ has been described by the HF/STO-3G method. The geometries were optimized without any symmetry constraints. Harmonic force constants were computed at the optimized geometries to characterize the stationary points as minima or saddle points. Zero-point vibrational corrections were determined from the harmonic vibrational frequencies to convert the total energies $E_{\mathrm{e}}$ to ground state energies $E_{0}$. The rigid-rotor harmonic-oscillator approximation was applied for evaluating the thermal and entropic contributions that are needed to derive the enthalpies $H_{298}$ and Gibbs free energies, $G_{298}$ at $298 \mathrm{~K}$. All transition states were located using the linear synchronous transit $(\mathrm{LST})^{13}$ method in which the reaction coordinate was kept fixed at different distances while all other degrees of freedom were relaxed. After the linear transit search, the transition states were optimized using the default Berny algorithm implemented in the Gaussian09 code. ${ }^{9}$ All transition states were confirmed by IRC (intrinsic reaction coordinate) calculations. For further validation, single-point calculations were performed at the M06-2X/LANL2TZ(Ru)/TZVP ( H, C, N, O and P) level of theory. Solvation energies $\left(E_{\mathrm{L}}^{S}\right)$ were evaluated by a self-consistent reaction field (SCRF) approach for all the intermediates and transitions states, using

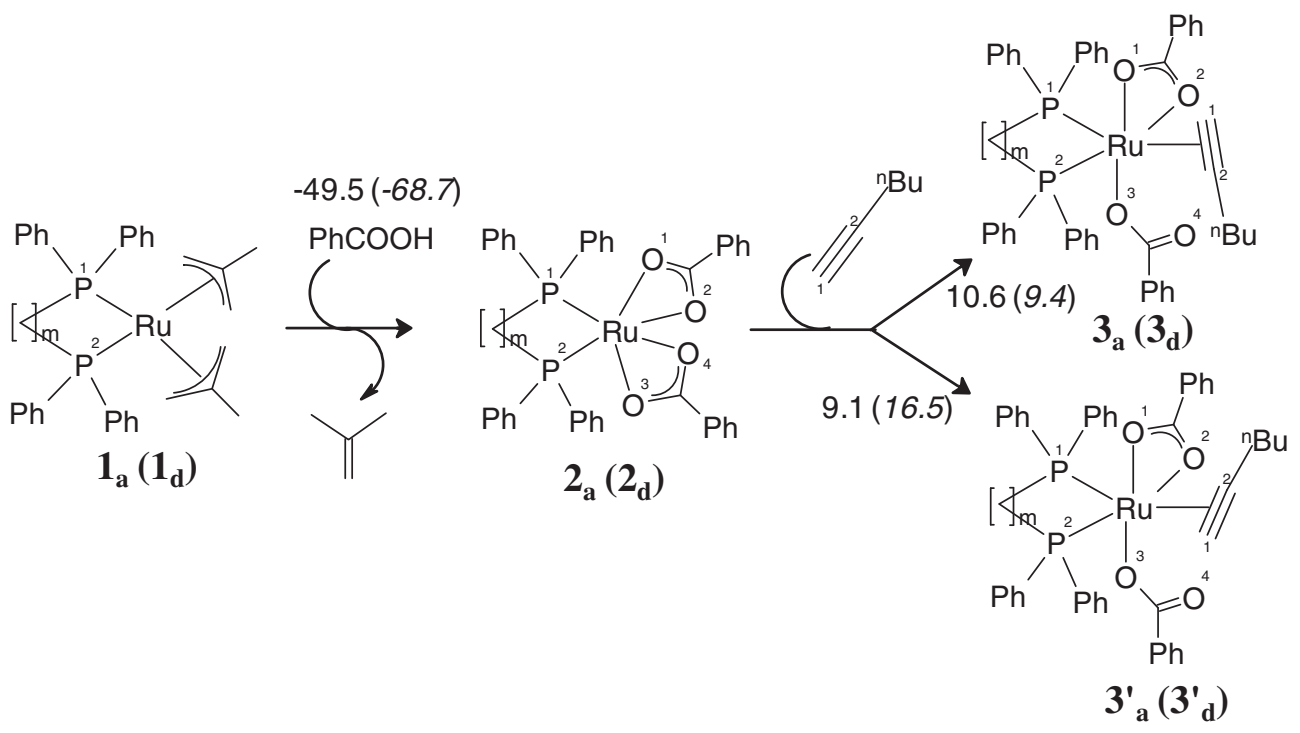

Scheme 3. Ligand exchange and alkyne coordination steps for $\mathbf{1 a} / \mathbf{d}$. The $\Delta G_{\mathrm{L}}^{S}$ energy terms (in $\mathrm{kcal} / \mathrm{mol}$ ) are represented for catalyst systems $\mathbf{1 a}(\mathbf{1 d})$. 
Table 1. Energy changes (in kcal/mol) for ligand exchange and 1-hexyne coordination steps involved in catalyst systems $\mathbf{1}_{\mathbf{a} / \mathbf{d}}$. For different energy terms, refer to computational details.

\begin{tabular}{lccccccccc}
\hline Steps & $\Delta E_{\mathrm{e}}$ & $\Delta H_{298}$ & $\Delta G_{298}$ & $\Delta E_{\mathrm{L}}^{S}$ & Steps & $\Delta E_{\mathrm{e}}$ & $\Delta H_{298}$ & $\Delta G_{298}$ & $\Delta E_{\mathrm{L}}^{S}$ \\
\hline $\mathbf{1 1}_{\mathbf{a}} \rightarrow \mathbf{2}_{\mathbf{a}}$ & -51.9 & -52.1 & -56.5 & -45.0 & $\mathbf{1 1}_{\mathbf{d}} \rightarrow \mathbf{2}_{\mathbf{d}}$ & -73.8 & -74.4 & -78.6 & -63.9 \\
$\mathbf{2 2}_{\mathbf{a}} \rightarrow \mathbf{3}_{\mathbf{a}}$ & -14.3 & -12.8 & 33.9 & -7.6 & $\mathbf{2 2}_{\mathbf{d}} \rightarrow \mathbf{3}_{\mathbf{d}}$ & -9.7 & -8.2 & 77.9 & -8.2 \\
$\mathbf{2 3}_{\mathbf{a}} \rightarrow \mathbf{3}_{\mathbf{a}}^{\prime}$ & -11.7 & -10.3 & 33.8 & -6.4 & $\mathbf{2 3}_{\mathbf{d}} \rightarrow \mathbf{3}_{\mathbf{d}}^{\prime}$ & -3.6 & -2.2 & 111.9 & 00.9 \\
\hline
\end{tabular}

the SMD continuum solvation model implemented in Gaussian09. ${ }^{14}$ Toluene was chosen as a solvent (dielectric constant $\varepsilon=2.374$ ) with SMD-intrinsic Coulomb radii for the respective atoms.

The different energy terms, $\Delta E_{\mathrm{e}}, \Delta H_{298}, \Delta G_{298}$, $\Delta E_{\mathrm{L}}^{S}$ and $\Delta G_{\mathrm{L}}^{S}$ represented in tables 1,3 and 4 (see text) are defined as follows. $\Delta E_{\mathrm{e}}$ is the total electronic energy change at ONIOM $\{\mathrm{M} 06-2 \mathrm{X} / \mathrm{LANL} 2 \mathrm{DZ}(\mathrm{Ru}) / 6-$ $31 \mathrm{G}^{*}(\mathrm{H}, \mathrm{C}, \mathrm{N}, \mathrm{O}$ and $\left.\mathrm{P}): \mathrm{HF} / \mathrm{STO}-3 \mathrm{G}\right\}$ level of theory, $\Delta H_{298}$ and $\Delta G_{298}$ are gas-phase enthalpy change and gas-phase Gibbs free energy change, respectively. $\Delta E_{\mathrm{L}}^{S}$ is the solvent electronic energy at M062X/LANL2TZ(Ru)/TZVP(H, C, N, O and P) level. Finally, $\Delta G_{\mathrm{L}}^{S}$ is the solvent-phase free energy change, where the total solvent electronic energy $\left(\Delta E_{\mathrm{L}}^{S}\right)$ is augmented with the gas-phase free energy correction at ONIOM\{M06-2X/LANL2DZ(Ru)/6-31G*(H, C, N, O and $\mathrm{P}): \mathrm{HF} / \mathrm{STO}-3 \mathrm{G}\}$ level. The charge distribution was analysed using the Weinhold's NPA (natural population analysis) approach. ${ }^{15}$

\section{Result and Discussions}

Experimental results of Dixneuf et al. showed that regio- and stereo-selectivity of carboxylic acid addition to the terminal alkynes can be modulated by the chain length connecting the phosphorous atoms of chelating bi-dentate phosphine ligand in catalyst $\mathbf{1}_{\mathbf{x}}(\mathrm{x}=$ $\mathrm{a}, \mathrm{b}, \mathrm{c}$ and $\mathrm{d}$; refer to scheme 1$){ }^{5 \mathrm{~b}}$ It was observed that catalyst containing one $\left(\mathrm{CH}_{2}\right)$ spacer group furnished predominantly the Markovnikov-added product I; whereas when four $\left(\mathrm{CH}_{2}\right)$ groups are used, a reversal of regio-selectivity occurs (scheme 1). Here, we have demonstrated the mechanism for two bi-dentate phosphine containing catalysts, $\mathbf{1}_{\mathrm{a}}$ and $\mathbf{1}_{\mathbf{d}}$, on the basis of calculated energy change of the key steps and NPA charges of the intermediates postulated in the proposed catalytic cycle (scheme 2). The reactivity and selectivity of other catalysts with homologous $b i$-dentate ligand $\left(\mathbf{1}_{\mathbf{b}}, \mathbf{1}_{\mathrm{c}}\right)$ and non-chelating phosphine ligands $\left(\mathbf{1}_{\mathbf{e}}\right.$ having two $\mathrm{PPh}_{3}$ instead of bi-dentate phosphine) are also examined and interpreted using NPA charges of the reactive atoms.
Under reaction temperature $\left(\sim 65^{\circ} \mathrm{C}\right)$ facile ligand exchange occurs in $\mathbf{1}_{\mathbf{x}}$ to yield the respective dicarboxylate complex $\mathbf{2}_{\mathbf{x}}$, which is considered as catalyst for the subsequent hexyne addition reaction (scheme 3). The high exothermicity for the step $\mathbf{1}_{\mathrm{x}} \rightarrow \mathbf{2}_{\mathrm{x}},\left(\mathbf{1}_{\mathrm{x}}\{\mathrm{x}=\mathrm{a}, \mathrm{b}, \mathrm{c}, \mathrm{d}\right.$ and $\mathrm{e}\}$ is, -49.5 , $-58.2,-62.0,-68.7$ and $-58.5 \mathrm{kcal} / \mathrm{mol}$; refer to table 1) is an obvious outcome due to two reasons: firstly, the facile removal of methallyl ligands as isobutene after protonation; and secondly, the stability gained by the coordination of the benzoate ions to the ruthenium(II) centre. Successful isolation of $\mathbf{2}_{\mathbf{d}}$ or its analogue [(bis(diphenylphosphino)butane) $\mathrm{Ru}\left(\eta^{2}-\right.$ $\left.\mathrm{O}_{2} \mathrm{CCF}_{3}\right)_{2}$ ] as reported under experimental conditions supports the calculated exothermicity of the ligand exchange process. Besides the electronic factor, stearic factor can also play a significant role. During replacement of methallyl ligands by benzoate ions, steric crowding around metal centre is reduced, the effect can be roughly quantified as $23.8 \mathrm{kcal} / \mathrm{mol}$ (for further details, refer to scheme $\mathrm{S} 1$ of supplementary information). Relative relaxation of the chelating phosphine ligand depends on its steric bulk; thus allowing the ligand exchange step for $\mathbf{1}_{\mathbf{d}}$ to be more exothermic than its lower homologues $\left(\mathbf{1}_{\mathrm{x}} ; \mathrm{x}=\mathrm{a}, \mathrm{b}\right.$ and $\left.\mathrm{c}\right)$.

It is well-known that coupling reaction of $\mathrm{X}-\mathrm{H}$ ( $\mathrm{X}-$ = RCOO-, RCONR-, RO-, RNH-, etc.) bonds to the alkyne occurs via two principal pathways: (i) oxidative addition of $\mathrm{X}-\mathrm{H}$ followed by alkyne insertion to metal-X bond, or (ii) alkyne coordination followed by nucleophilic attack to the coordinated alkyne. The former pathway would be preferred for catalytic systems having electron-rich metal center with small coordination number. However, in

Table 2. NPA charges on the selective atoms ( $\mathrm{Ru}, \mathrm{C} 1$ and C2) of alkyne coordinated complexes $\mathbf{3}_{\mathbf{x}}$.

\begin{tabular}{lccc}
\hline Complex & $q_{\mathrm{Ru}}$ & $q_{\mathrm{C} 1}$ & $q_{\mathrm{C} 2}$ \\
\hline $\mathbf{3}_{\mathbf{a}}$ & -0.246 & -0.246 & 0.126 \\
$\mathbf{3}_{\mathbf{b}}$ & -0.227 & -0.243 & 0.059 \\
$\mathbf{3}_{\mathbf{c}}$ & -0.243 & -0.257 & 0.074 \\
$\mathbf{3}_{\mathbf{d}}$ & -0.255 & -0.230 & 0.022 \\
$\mathbf{3}_{\mathbf{e}}$ & -0.144 & -0.288 & 0.151 \\
\hline
\end{tabular}


octahedral complex $\mathbf{2}_{\mathbf{x}}$, the ruthenium(II) center is both coordinatively saturated and electron deficient precluding the possibility to follow the coupling pathway (i) as mentioned earlier. Alternatively, we can also think of a possibility where alkyne insertion to the $\mathrm{Ru}-\mathrm{O}$ bond occurs in $\mathbf{2}_{\mathbf{x}}$. However, experimental finding supports the external attack of carboxylate rather than the one already coordinated to the ruthenium center. ${ }^{5 \mathrm{~b}}$ Hence, pathway (ii) stands out to as the only route for the coupling reaction.

During the subsequent hexyne coordination in $\mathbf{2}_{\mathbf{x}}$, one of the $\mathrm{Ru}-\mathrm{O}$ bonds cleaves, providing ample room for the incoming ligand to form the $\eta^{2}$-complex $\mathbf{3}_{\mathbf{x}}$ (scheme 3). Closer inspection of $\mathbf{2}_{\mathrm{x}}$ geometries reveal that the $\mathrm{Ru}-\mathrm{O} 2 / \mathrm{O} 4$ bonds are more elongated than the $\mathrm{Ru}-\mathrm{O} 1 / \mathrm{O} 3$ bonds $\left(\mathrm{r}_{\mathrm{Ru}-\mathrm{O} 1}\left(\mathbf{2}_{\mathrm{a}} / \mathbf{2}_{\mathbf{d}}\right)=2.143 / 2.166 \AA\right.$, $\mathrm{r}_{\mathrm{Ru}-\mathrm{O} 2}\left(\mathbf{2}_{\mathrm{a}} / \mathbf{2}_{\mathrm{d}}\right)=2.207 / 2.244 \AA, \quad \mathrm{r}_{\mathrm{Ru}-\mathrm{O} 3}\left(\mathbf{2}_{\mathrm{a}} / \mathbf{2}_{\mathrm{d}}\right)=2.142 / 2$. $142 \AA$ and $\mathrm{r}_{\mathrm{Ru}-\mathrm{O} 4}\left(\mathbf{2}_{\mathrm{a}} / \mathbf{2}_{\mathrm{d}}\right)=2.224 / 2.237 \AA$ ). It is also observed that $\mathrm{O} 1 / \mathrm{O} 3$ orients to the site crowded with two cis phosphorus atoms (P1 and $\mathrm{P} 2$ ); whereas in $\mathrm{O} 2 / \mathrm{O} 4$, one phosphorus is cis- and other trans- (figure S1). The combined effect of such spatial disposition of ligands creates a sterically less demanding environment for the incoming hexyne to coordinate from the $\mathrm{O} 2 / \mathrm{O} 4$ site. The coordination of hexyne results in two isomeric intermediates $\left(\mathbf{3}_{\mathbf{x}}, \mathbf{3}_{\mathbf{x}}^{\prime}\right.$, scheme 2$)$, differing only in the orientation of the $n$-butyl chain. As usual, the coordination step $\mathbf{2}_{\mathrm{x}} \rightarrow \mathbf{3}_{\mathrm{x}} / \mathbf{3}_{\mathrm{x}}^{\prime}$ is exothermic for the studied set of ligands, but endergonic due to the entropic penalty associated with ligand combination (refer to table 1). Surprisingly, there exists no trend in the relative stabilities of the intermediates $\mathbf{3}_{\mathbf{x}}$ and $\mathbf{3}_{\mathbf{x}}^{\prime}$. In case of catalytic system $\mathbf{1}_{\mathrm{a}}$, isomer $\mathbf{3}_{\mathrm{a}}^{\prime}$ is more stable than $\mathbf{3}_{\mathrm{a}}$. In contrast, the reverse is seen for catalytic system $\mathbf{1}_{\mathbf{d}}$ $\left(\Delta \mathrm{G}_{\mathrm{L}}^{\mathrm{S}}\left(\mathbf{3}_{\mathrm{a}} \rightarrow \mathbf{3}_{\mathrm{a}}^{\prime} / \mathbf{3}_{\mathbf{d}} \rightarrow \mathbf{3}_{\mathbf{d}}^{\prime}\right)=-1.5 / 7.1 \mathrm{kcal} / \mathrm{mol}\right)$.

\subsection{Markovnikov addition}

Markovnikov product would be generated if the benzoic acid attacks $\mathrm{C} 2$ of the coordinated $\eta^{2}-\mathrm{Ru}$ (II) hexyne species. In intermediates $\mathbf{3}_{\mathbf{x}} / \mathbf{3}_{\mathbf{x}}^{\prime}$, the atoms $\mathrm{C} 1$ and $\mathrm{C} 2$ represent nucleophilic and electrophilic centers, respectively, as obvious from the NPA charges tabulated in table 2. Hence, the benzoic acid should preferentially attack at the $\mathrm{C} 2$ positions leading to the intermediate $\mathbf{4}_{\mathbf{x}}$ which will eventually produce the Markovnikov addition product I (schemes 1 and 4 ). We can surmise that the scope of Markovnikov product formation depends upon the magnitude of positive charge on $\mathrm{C} 2$ atom in $\mathbf{3}_{\mathrm{x}} / \mathbf{3}_{\mathbf{x}}^{\prime}$. To understand the wider role of ligands in modulating the regio-selectivity of product formation, we have studied the benzoic acid addition to the selected intermediates $\mathbf{3}_{\mathrm{a}}$ and $\mathbf{3}_{\mathrm{d}}$, respectively. Since the $\mathrm{C} 2$ charge separation is negligible between $\boldsymbol{3}_{\mathbf{x}}$ and $\mathbf{3}_{\mathrm{x}}^{\prime}$, we have only considered the nucleophilic addition step for $\mathbf{3}_{\mathbf{a}}\left(\Delta q_{\mathrm{C} 2}=-0.010 e\right.$ from $\mathbf{3}_{\mathbf{a}}$ to $\left.\mathbf{3}_{\mathbf{a}}^{\prime}\right)$ and $\mathbf{3}_{\mathbf{d}}$ $\left(\Delta q_{\mathrm{C} 2}=0.002 e\right.$ from $\mathbf{3}_{\mathbf{d}}$ to $\left.\mathbf{3}_{\mathbf{d}}^{\prime}\right)$ intermediates, which are supposed to furnish different regio-addition products as experimentally reported. To explore the reaction surface, the benzoic acid was gradually allowed to attack the $\mathrm{C} 2$ centres of $\mathbf{3}_{\mathrm{a}}$ and $\mathbf{3}_{\mathrm{d}}$. Interestingly, the calculated activation barrier for the step $\mathbf{3}_{\mathbf{a}} \rightarrow \mathbf{4}_{\mathrm{a}}$ is substantially higher than the one in $\mathbf{3}_{\mathbf{d}} \rightarrow \mathbf{4}_{\mathbf{d}}\left(\Delta^{\ddagger} G_{\mathrm{L}}^{S}=\right.$ $25.8 \mathrm{kcal} / \mathrm{mol}$ for $\mathbf{3}_{\mathrm{a}} \rightarrow \mathbf{4}_{\mathrm{a}}$ vs. $\Delta^{\ddagger} G_{\mathrm{L}}^{S}=45.3 \mathrm{kcal} / \mathrm{mol}$ for $\mathbf{3}_{\mathbf{d}} \rightarrow \mathbf{4}_{\mathbf{d}}$; scheme 4 and table 3 ). It is not surprising that the activation barrier has strong correlation with the positive charge at the $\mathrm{C} 2$ centre $\left(q_{\mathrm{C} 2}\left(\mathbf{3}_{\mathrm{a}} / \mathbf{3}_{\mathrm{d}}\right)=\right.$ $0.126 / 0.022 e$, table 2$)$. The optimized transition states $\left[\mathbf{3}_{\mathrm{a}}-\mathbf{4}_{\mathrm{a}}\right]^{\ddagger}$ and $\left[\mathbf{3}_{\mathrm{d}}-\mathbf{4}_{\mathrm{d}}\right]^{\ddagger}$ are characterized with an eigenmode of decent magnitude $\left(-370 i \mathrm{~cm}^{-1}\right.$ in $\left[\mathbf{3}_{\mathbf{a}}-\mathbf{4}_{\mathbf{a}}\right]^{\ddagger}$ vs. $-427 i \mathrm{~cm}^{-1}$ in $\left.\left[\mathbf{3}_{\mathrm{d}}-\mathbf{4}_{\mathrm{d}}\right]^{\ddagger}\right)$ animating the attack of oxygen atom on $\mathrm{PhCOOH}$ towards $\mathrm{C} 2$ with concomitant transfer of acid hydrogen (H2) atom to $\mathrm{O} 2$ of coordinated benzoate (figure 1 ). In intermediate $\mathbf{4}_{\mathrm{a} / \mathbf{d}}$, the $\mathrm{O} 2$ from one of the benzoates has protonated during the addition step while the $\mathrm{O} 4$ from other benzoate regains its bonding to saturate the coordination at the ruthenium center. The geometrical parameters of $\mathbf{4}_{\mathrm{a} / \mathrm{d}}$ resemble a typical vinyl intermediate. The $\mathrm{C} 1-\mathrm{C} 2$ bond lengths are $1.337 / 1.339 \AA$ and $\perp \mathrm{Ru}-\mathrm{C} 1-\mathrm{C} 2$ angles $135.6 / 135.9^{\circ}$, which are in good agreement with previously calculated result by Caulton in the $\mathrm{RuHCl}\left(\mathrm{CH}=\mathrm{CH}_{2}\right)\left(\mathrm{PH}_{3}\right)_{2}$ intermediate. ${ }^{16}$ During the subsequent step of the reaction, the final Markovnikov product I will be liberated with the regeneration of catalyst $\mathbf{2}_{\mathbf{a} / \mathbf{d}}$.
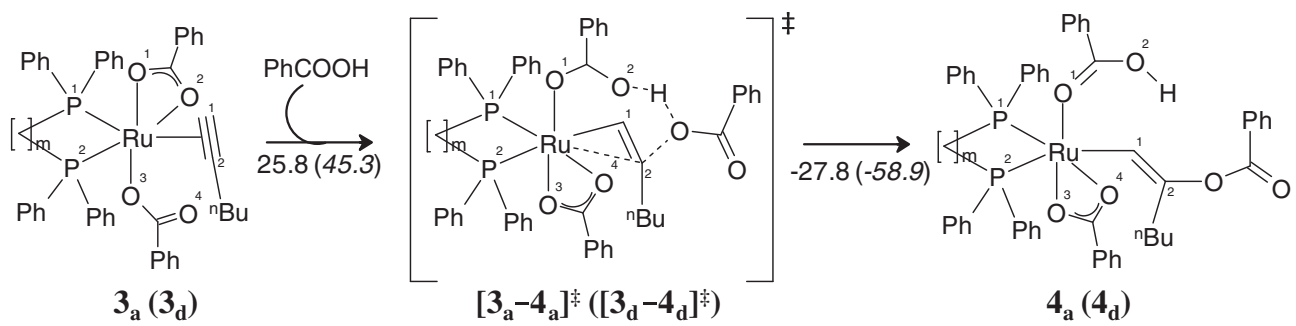

Scheme 4. Markovnikov product formation pathway. For energy conventions see scheme 2. 
Table 3. Energy changes (in $\mathrm{kcal} / \mathrm{mol}$ ) for nucleophilic attack on the alkyne coordinated complex. For different energy terms, refer to computational details.

\begin{tabular}{lccccccccc}
\hline Steps & $\Delta E_{\mathrm{e}}$ & $\Delta H_{298}$ & $\Delta G_{298}$ & $\Delta E_{\mathrm{L}}^{S}$ & Steps & $\Delta E_{\mathrm{e}}$ & $\Delta H_{298}$ & $\Delta G_{298}$ & $\Delta E_{\mathrm{L}}^{S}$ \\
\hline $\mathbf{3}_{\mathbf{a}} \rightarrow\left[\mathbf{3}_{\mathrm{a}}-\mathbf{4}_{\mathbf{a}}\right]^{\ddagger}$ & 17.3 & 15.9 & 20.7 & 22.4 & $\mathbf{3}_{\mathbf{d}} \rightarrow\left[\mathbf{3}_{\mathbf{d}}-\mathbf{4}_{\mathbf{d}}\right]^{\ddagger}$ & 34.6 & 38.1 & 43.4 & 36.5 \\
{$\left[\mathbf{3}_{\mathbf{a}}-\mathbf{4}_{\mathbf{a}}\right]^{\ddagger} \rightarrow \mathbf{4}_{\mathbf{a}}$} & -38.3 & -34.7 & -27.4 & -42.5 & {$\left[\mathbf{3}_{\mathbf{d}}-\mathbf{4}_{\mathbf{d}}\right]^{\ddagger} \rightarrow \mathbf{4}_{\mathbf{d}}$} & -58.9 & -60.1 & -53.7 & -43.2 \\
\hline
\end{tabular}
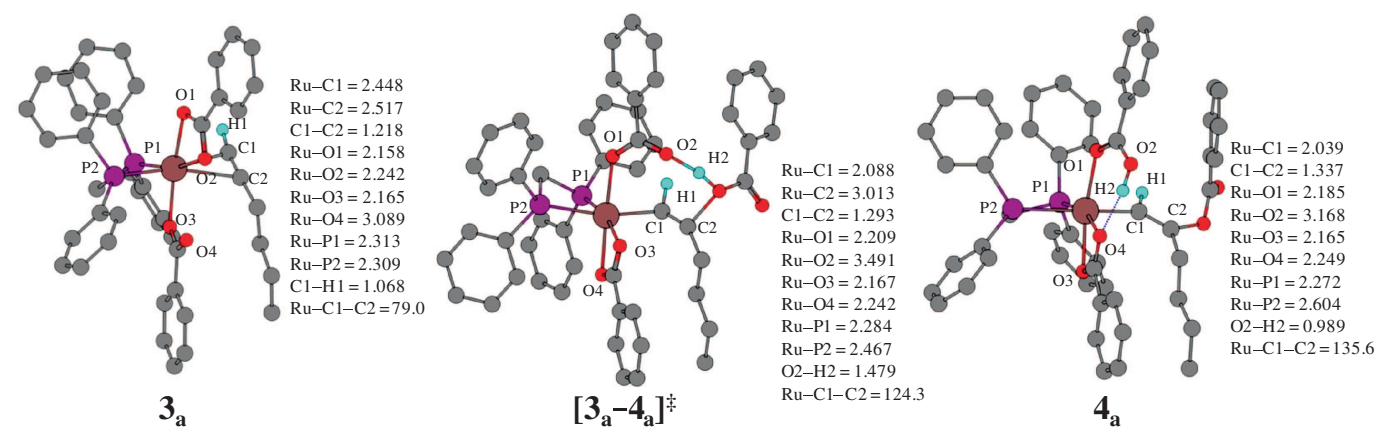

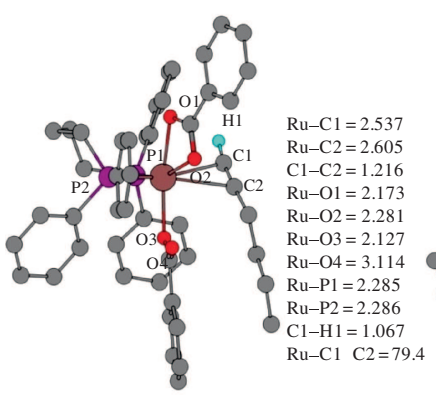

$\mathbf{3}_{\mathrm{d}}$

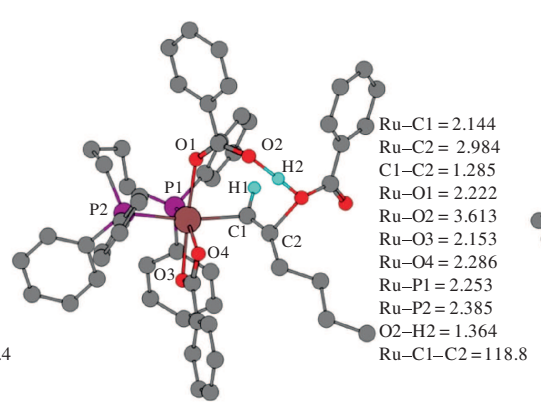

$\left[\mathbf{3}_{\mathrm{d}}-\mathbf{4}_{\mathrm{d}}\right]^{\ddagger}$

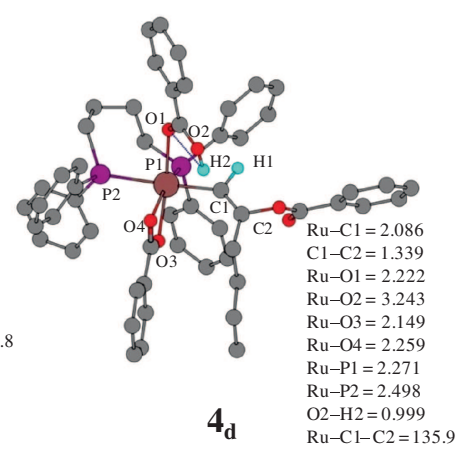

Figure 1. Optimized geometries of intermediates and transition states involve in nucleophilic addition step to the $\mathbf{3}_{\mathbf{a} / \mathbf{d}}$. Hydrogen atoms are omitted for clarity. All bond lengths are in angstrom ( $)$ and angles in degree $\left({ }^{\circ}\right)$.

The calculated NPA charges (table 2) of $\mathrm{C} 2$ atom for intermediates $\boldsymbol{3}_{\mathbf{a}}$ to $\boldsymbol{3}_{\mathbf{d}}$ are in the order of $\mathbf{3}_{\mathrm{a}}>\mathbf{3}_{\mathrm{c}}>\mathbf{3}_{\mathrm{b}}>\mathbf{3}_{\mathrm{d}}$. Considering the calculated results for benzoic acid addition (vide supra) and the NPA charges at the $\mathrm{C} 2$ centre, it is understandable to believe that the extent of positive charge at the $\mathrm{C} 2$ center will dictate the feasibility of Markovnikov addition to occur. Indeed, the experimental results fully substantiate our understanding. To further support our statement, the C2 charge on monodentate phosphine containing isomer $\mathbf{3}_{\mathrm{e}}$ is highest among the studied $\mathbf{3}_{\mathbf{x}}$ intermediates suggesting an exclusive formation of Markovnikov addition product. This supports the experimental findings of Gooßen et al. on vinyl ester formation using ruthenium catalysed addition of carboxylic acids to alkynes. ${ }^{7}$

\subsection{Anti-Markovnikov addition}

In general, the anti-Markovnikov product formation can occur if the nucleophile coordinates to the $\mathrm{C} 1$ centre of the $\eta^{2}-\mathrm{Ru}(\mathrm{II})$ intermediate $\mathbf{3}_{\mathbf{x}}$. However, the electron-rich $\mathrm{C} 1$ center for $\mathbf{3}_{\mathbf{x}}$ complexes (table 2) hinders the direct approach of any nucleophile; thus precluding the formation of anti-Markovnikov products (II and III). Therefore, formation of anti-Markovnikov product via direct nucleophilic attack to the alkyne coordinated complex is ruled out. To explain the regioselectivity of nucleophilic addition, Dixneuf et al. proposed an isomer 3_i (scheme 3), where C1 possesses a partially positive charge. Unfortunately, such geometry did not converge during DFT optimization. To the best of our knowledge, an electrophilic $\mathrm{C} 1$ center can be obtained, if a conversion route for the $\mathbf{3}_{\mathbf{x}}$ intermediates to transform to their respective vinylidene isomers exists. A theoretical study of vinylidene complexes by Kostic and Fenske identified the electron deficiency at $\mathrm{C} 1$ and the localization of electron density in the $\mathrm{M}=\mathrm{C}$ double bond. ${ }^{17}$ Hence, it is important at this stage to search for probable pathways for vinylidene formation. From $\mathbf{3}_{\mathbf{x}}$, two different pathways leading to neutral 
and cationic vinylidene intermediates are calculated as discussed here.

\section{2a Neutral vinylidene formation pathway:} Dixneuf proposed a mechanism for the formation of ruthenium vinylidene complex via 1,2-proton shift at the alkyne coordinated moiety $\mathbf{3}_{\mathbf{x}} \cdot{ }^{8 \mathrm{~b}, 18}$ While investigating the mechanism of vinylidene formation in water addition to alkynes, Saá et al. reported a similar 1,2-proton shift supported by isotopic labelling experiment. ${ }^{19}$ Considering the above facts, we studied the transfer of the acetylinic hydrogen ( $\mathrm{H} 1)$ atom from $\mathrm{C} 1$ to $\mathrm{C} 2$ in both $\mathbf{3}_{\mathbf{a} / \mathbf{d}}$ intermediates (scheme 5). The vinylidene intermediate, $\mathbf{5}_{\mathbf{a} / \mathbf{d}}$, formed after such proton transfers is more unstable than its hexyne coordinated predecessor by $12.7 / 17.5 \mathrm{kcal} / \mathrm{mol}$. A similar endothermicity for vinylidene formation was also reported by Dixneuf and Morokuma for the complex of type $\mathrm{RuX}_{2}(\mathrm{RC} \equiv \mathrm{CH})\left(\mathrm{PR}_{3}\right)_{2} \cdot{ }^{17,20}$

The hydrogen atoms $(\mathrm{H} 1)$ in transition states $\left[\mathbf{3}_{\mathrm{a}}-\mathbf{5}_{\mathrm{a}}\right]^{\ddagger}$ and $\left[\mathbf{3}_{\mathbf{d}}-\mathbf{5}_{\mathbf{d}}\right]^{\ddagger}$ are more positive $\left(q_{\mathrm{H} 1}\left(\left[\mathbf{3}_{\mathbf{a}}-\mathbf{5}_{\mathbf{a}}\right]^{\ddagger} /\left[\mathbf{3}_{\mathbf{d}}-\mathbf{5}_{\mathbf{d}}\right]^{\ddagger}\right)\right.$ $=0.386 / 0.385 e)$ than the connecting intermediates $\mathbf{3}_{\mathrm{a} / \mathbf{d}}$ and $\mathbf{5}_{\mathbf{a} / \mathbf{d}}\left(q_{\mathrm{H} 1}\left(\mathbf{3}_{\mathbf{a}} / \mathbf{3}_{\mathbf{d}}\right)=0.266 / 0.272 e\right.$ and $q_{\mathrm{H} 1}\left(\mathbf{5}_{\mathbf{a}} / \mathbf{5}_{\mathbf{d}}\right)=$ $0.256 / 0.258 e$ ) indicating a proton shift accompanying the vinylidene formation step. The activation barrier for $\mathbf{3}_{\mathrm{a}} \rightarrow \mathbf{5}_{\mathrm{a}}$ is slightly higher than that of $\mathbf{3}_{\mathbf{d}} \rightarrow \mathbf{5}_{\mathbf{d}}$ step by $7.5 \mathrm{kcal} / \mathrm{mol}\left(\Delta^{\ddagger} G_{\mathrm{L}}^{S}\left(\mathbf{3}_{\mathrm{a}} \rightarrow \mathbf{5}_{\mathrm{a}} / \mathbf{3}_{\mathbf{d}} \rightarrow \mathbf{5}_{\mathbf{d}}\right)=40.8 / 33.3\right.$ $\mathrm{kcal} / \mathrm{mol}$, refer to table 4$)$. A probable explanation rests on the electronic charges on the $\mathrm{C} 2$ atoms in $\mathbf{3}_{\mathrm{a} / \mathbf{d}}$ intermediates. The more positive charge on $\mathrm{C} 2$ in $\mathbf{3}_{\mathrm{a}}\left(\mathrm{q}_{\mathrm{C} 2}=\right.$ $0.126 e$ ) hinders the approach of the incoming proton resulting in a higher barrier than in $\mathbf{3}_{\mathbf{d}}$ (table 2). Under similar grounds, we can justify the reluctance of $\mathbf{3}_{\mathrm{e}}$ to transform to vinylidene intermediate, since $\mathrm{C} 2$ is the most electron deficient among the $\mathbf{3}_{\mathbf{x}}$ intermediates (table 2). The imaginary frequencies of the transition states $\left[\mathbf{3}_{\mathbf{a}}-\mathbf{5}_{\mathbf{a}}\right]^{\ddagger}$ and $\left[\mathbf{3}_{\mathbf{d}}-\mathbf{5}_{\mathbf{d}}\right]^{\ddagger}$ depicts the correct mode, involving the oscillation of hydrogen (H1) between $\mathrm{C} 1$ and $\mathrm{C} 2$ atoms. The calculated activation barriers and the geometrical parameters (see figure 2) of the optimized transition states resemble the DFT results reported by Wakatsuki et al., while investigating the hydration of alkynes using ruthenium(II) catalyst. ${ }^{21}$ The vinylidene complexes, $\mathbf{5}_{\mathbf{a} / \mathbf{d}}$ can now undergo the usual nucleophilic addition at the $\mathrm{C} 1$ center to form the anti-Markovnikov enol esters II and III (scheme 1).

3.2b Cationic vinylidene formation pathway: There exists a different pathway for vinylidene formation via $\mathrm{Ru}$-vinyl intermediates as proposed by Wakatsuki et al. during their study of water addition to terminal alkynes. $^{21}$ In search of similar Ru(II)-vinyl intermediates, we conducted protonation at the $\mathrm{C} 2$ center of $\mathbf{3}_{\mathbf{a} / \mathbf{d}}$. After addition of proton at C2 atom in $\mathbf{3}_{\mathbf{a}}$, ruthenium(II) vinyl intermediate $\mathbf{3}_{\mathrm{a}}$-vin is formed as depicted in scheme 6 . We have noticed a migration of proton to $\mathrm{C} 1$ center with subsequent coordination of $\mathrm{O} 4$ to $\mathrm{C} 2$, leading to an intramolecular ligation of the benzoate ion. It is clear that intermediate $\mathbf{3}_{\mathbf{a}}$-vin after subsequent transformation will produce the desired Markovnikov product I. In contrast, similar protonation in $\mathbf{3}_{\mathbf{d}}$ furnished a typical ruthenium(II) vinyl intermediate $\mathbf{3}_{\mathbf{d}}$-vin, where no intramolecular coordination of benzoate to C2 occurs. Unfortunately, the step $\mathbf{3}_{\mathbf{d}} \rightarrow \mathbf{3}_{\mathrm{d}}$-vin is highly endothermic $\left(\Delta G_{\mathrm{L}}^{S}=77.1 \mathrm{kcal} / \mathrm{mol}\right)$ making its existence doubtful under the reaction condition.

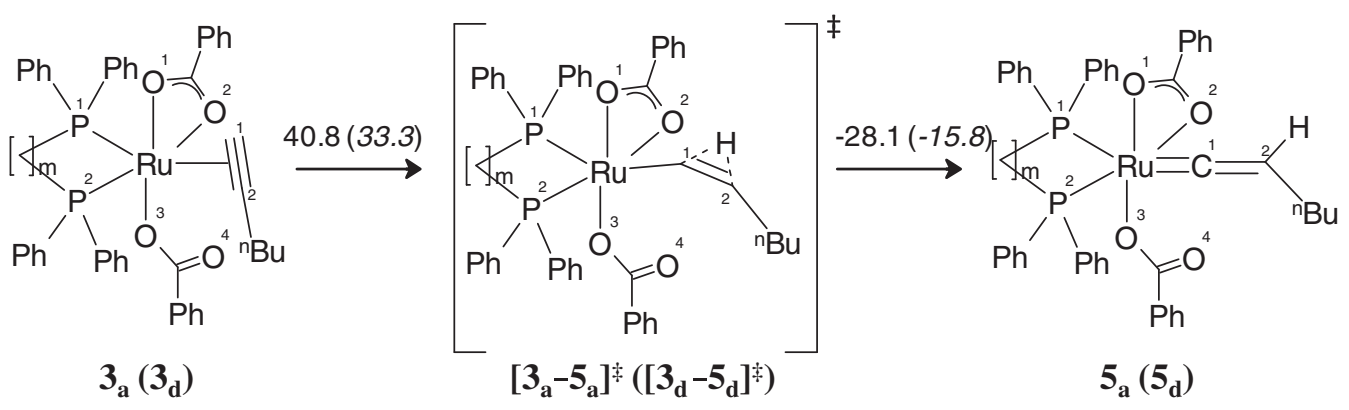

Scheme 5. Neutral vinylidene formation pathway. For energy conventions see scheme 2.

Table 4. Energy changes (in $\mathrm{kcal} / \mathrm{mol}$ ) for the step of vinylidene formation from alkyne coordinated complexes, $\mathbf{3}_{\mathbf{a}}$ and $\mathbf{3}_{\mathbf{d}}$. For different energy terms, refer to computational details.

\begin{tabular}{|c|c|c|c|c|c|c|c|c|c|}
\hline Steps & $\Delta E_{\mathrm{e}}$ & $\Delta H_{298}$ & $\Delta G_{298}$ & $\Delta E_{\mathrm{L}}^{S}$ & Steps & $\Delta E_{\mathrm{e}}$ & $\Delta H_{298}$ & $\Delta G_{298}$ & $\Delta E_{\mathrm{L}}^{S}$ \\
\hline $\begin{array}{l}\mathbf{3}_{\mathrm{a}} \rightarrow\left[\mathbf{3}_{\mathrm{a}}-\mathbf{5}_{\mathrm{a}}\right]^{\ddagger} \\
{\left[\mathbf{3}_{\mathrm{a}}-\mathbf{5}_{\mathrm{a}}\right]^{\ddagger} \rightarrow \mathbf{5}_{\mathrm{a}}}\end{array}$ & $\begin{array}{c}41.6 \\
-33.7\end{array}$ & $\begin{array}{c}33.3 \\
-25.4\end{array}$ & $\begin{array}{c}41.1 \\
-34.3\end{array}$ & $\begin{array}{l}41.3 \\
-7.5\end{array}$ & $\begin{array}{c}\mathbf{3}_{\mathbf{d}} \rightarrow\left[\mathbf{3}_{\mathbf{d}}-\mathbf{5}_{\mathbf{d}}\right]^{\ddagger} \\
{\left[\mathbf{3}_{\mathbf{d}}-\mathbf{5}_{\mathbf{d}}\right]^{\ddagger} \rightarrow 5_{\mathrm{d}}}\end{array}$ & $\begin{array}{c}33.4 \\
-18.3\end{array}$ & $\begin{array}{c}35.5 \\
-20.4\end{array}$ & $\begin{array}{c}35.7 \\
-21.9\end{array}$ & $\begin{array}{c}31.0 \\
-12.2\end{array}$ \\
\hline
\end{tabular}




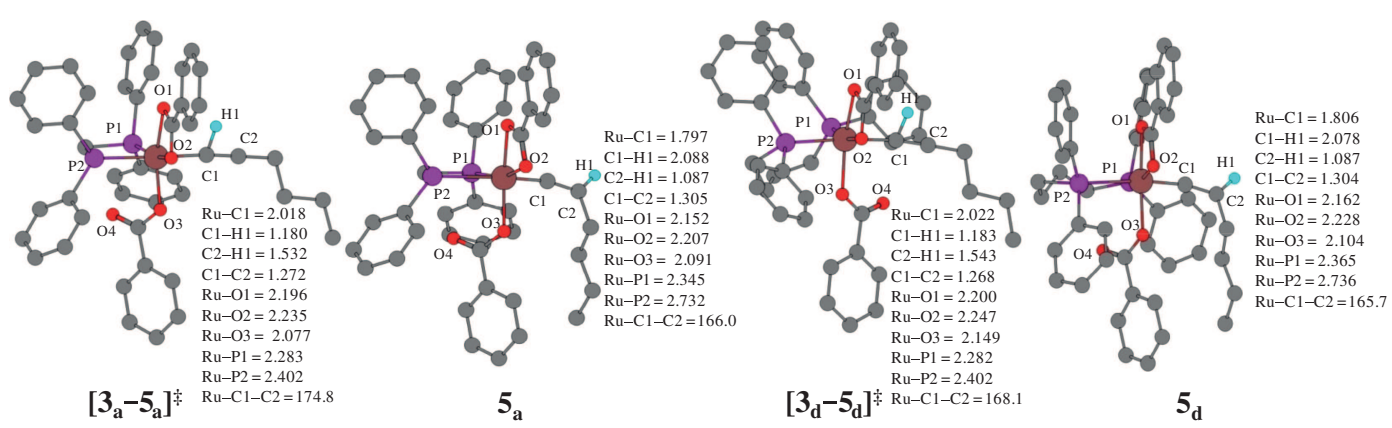

Figure 2. Optimized geometries of intermediates and transition states involve in neutral vinylidene formation step. For other conventions, see figure 1.

We have also investigated an alternative route for generation of cationic vinylidene intermediates (scheme 7) considering the oxidative addition of alkyne via $\mathrm{C} 1-\mathrm{H}$ bond activation at the ruthenium center $^{22}$ followed by protonation at the $\mathrm{C} 2$ center. DFT calculations by Wakatsuki showed that oxidative addition of $\mathrm{C}^{\mathrm{sp}}-\mathrm{H}$ bond of coordinated 1-alkyne to the ruthenium(II) intermediate was unfavourable due to very high activation barrier of $40.3 \mathrm{kcal} / \mathrm{mol}\left(\Delta^{\ddagger} H_{298}\right)$ at B3LYP/LANL2DZ(Ru)/6-31G(d)(C, H, O and P) level of theory. A similar oxidative addition pathway was studied for intermediate $\boldsymbol{3}_{\mathrm{d}}$. The optimized geometry of the oxidatively added Ru(IV)-hydrido-alkynyl complex $\left(\mathbf{6}_{\mathbf{d}}\right.$, figure $\left.\mathrm{S} 2\right)$ is $41.8 \mathrm{kcal} / \mathrm{mol}\left(\Delta G_{\mathrm{L}}^{S}\right)$ unstable than $\mathbf{3}_{\mathbf{d}}$, indicating a high activation barrier to surmount. We were also curious to explore a similar possibility for $\mathbf{3}_{\mathbf{a} / \mathbf{d}}^{\prime}$ intermediates. We were unable to optimize the desired $\mathrm{Ru}(\mathrm{IV})$-hydrido-alkynyl complex; instead the $\mathrm{H} 1$ atom migrated to the $\mathrm{O} 4$ center leading to a new ruthenium(II)-alkynyl complexes $\mathbf{6}_{\mathbf{a} / \mathbf{d}}^{\prime}$ (scheme 7). The overall step $\left(\mathbf{3}_{\mathbf{a} / \mathbf{d}}^{\prime} \rightarrow \mathbf{6}_{\mathbf{a} / \mathbf{d}}^{\prime}\right)$ is endergonic by $4.6 / 9.2 \mathrm{kcal} / \mathrm{mol}\left(\Delta H_{298}\right.$, table 5$)$, a value which is in good agreement with the result reported by Wakatsuki $\left(\Delta H_{298}=9 \mathrm{kcal} / \mathrm{mol}\right) .{ }^{21}$ The calculated activation barriers $\left(\Delta^{\ddagger} G_{\mathrm{L}}^{S}\left(\mathbf{3}_{\mathbf{a}}^{\prime} \rightarrow \mathbf{6}_{\mathbf{a}}^{\prime} / \mathbf{3}_{\mathbf{d}}^{\prime} \rightarrow \mathbf{6}_{\mathbf{d}}^{\prime}=13.0 / 6.5 \mathrm{kcal} / \mathrm{mol}\right)\right.$ are comparatively lower than usual oxidative addition $\left(\Delta^{\ddagger} E_{\mathrm{e}}=18.9 \mathrm{kcal} / \mathrm{mol}\right.$ at B3LYP/LANL2DZ $(\mathrm{Ru}) / 6$ $31 \mathrm{G}(\mathrm{d}, \mathrm{p})(\mathrm{C}, \mathrm{H}, \mathrm{O}$ and $\mathrm{P})$ label of theory) investigated by Gimeno et al. ${ }^{23}$
In alkynyl complexes $\mathbf{6}_{\mathbf{a} / \mathbf{d}}^{\prime}$, the $\mathrm{C} 1-\mathrm{C} 2$ distances are $1.224 / 1.221 \AA$ comparable to the reported value of $1.222 \AA$ in $\left[\mathrm{Ru}(\mathrm{IV}) \mathrm{Cp} *(\mathrm{H})\left(\mathrm{C} \equiv \mathrm{CMe}\left(\mathrm{PH}_{3}\right)_{2}\right]^{+}\right.$intermediate. ${ }^{21}$ In complexes $\mathbf{6}_{\mathbf{a} / \mathbf{d}}^{\prime}$, substantial electron densities at $\mathrm{C} 1$ and $\mathrm{C} 2$ atoms $\left(q_{\mathrm{C} 1}\left(\mathbf{6}_{\mathbf{a} / \mathbf{d}}^{\prime}\right)=-0.143 /\right.$ $\left.-0.124 e ; q_{\mathrm{C} 2}\left(6_{\mathbf{a} / \mathbf{d}}^{\prime}\right)=-0.130 /-0.169 e\right)$, prohibit any nucleophilic attack at these centres. In 1986, Consiglio et al. showed experimentally that ruthenium-alkynyl complexes can be converted into vinylidene species in presence of protic acid. ${ }^{24}$ Following the same line of thought, we have added a proton to $\mathrm{C} 2$ of $\mathbf{6}_{\mathbf{a} / \mathbf{d}}^{\prime}$ resulting in cationic vinylidene intermediates $7_{\mathbf{a} / \mathbf{d}}^{\prime}$ (see scheme 7 and figure 2) as shown in figure 3. The protonation $\operatorname{step}\left(\mathbf{6}_{\mathrm{a} / \mathbf{d}}^{\prime} \rightarrow 7_{\mathrm{a} / \mathbf{d}}^{\prime}\right)$ of the alkynyl isomers entails a moderately high endothermicity of 43.7 and 45.4 $\mathrm{kcal} / \mathrm{mol}$ (scheme 7 and table 5).

The deuterium labelling experiment conducted by Wakatsuki confirms that the acetylinic hydrogen does not migrate to the $\mathrm{C} 2$ center as discussed in the neutral vinylidene formation pathway. The study proposed that a cationic pathway should be followed in case of hydration of alkynes in alcohol medium. However, our calculated results support the neutral vinylidenes $\left(\mathbf{5}_{\mathbf{a} / \mathbf{d}}\right)$ formation via 1,2-proton shift to be energetically more favourable than the cationic vinylidene $\left(7_{\mathrm{a} / \mathbf{d}}^{\prime}\right)$ route. ${ }^{25}$ The contradiction arises probably due to the polarity of the employed solvent, as the charge species under non-polar solvent, here toluene, is not stabilized. Gooßen et al. have also proposed the presence
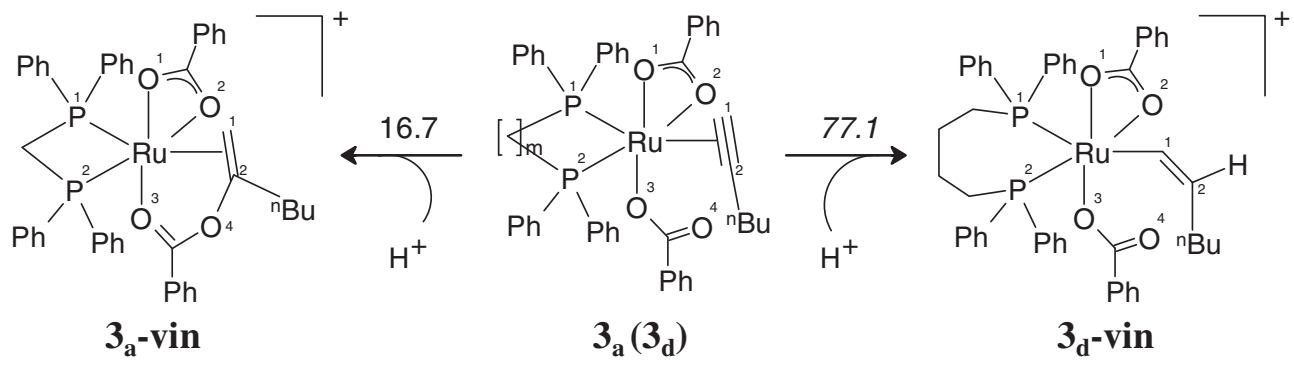

Scheme 6. Cationic vinyl formation step. For energy conventions, see scheme 2. 

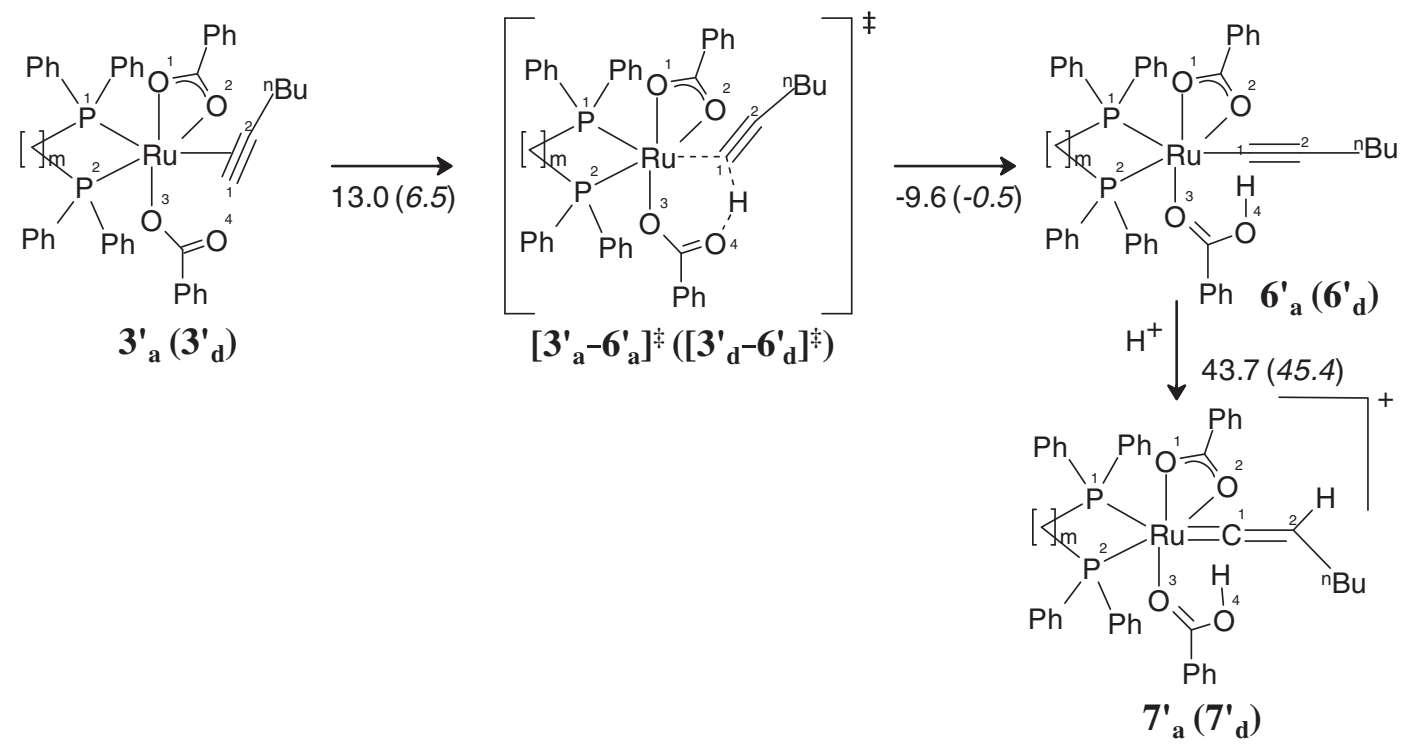

Scheme 7. Cationic vinylidene formation pathway via alkynyl intermediate.

Table 5. Energy changes (in $\mathrm{kcal} / \mathrm{mol}$ ) for the step of cationic vinylidene formation from alkyne coordinated complexes, $\mathbf{3}_{\mathbf{a} / \mathbf{d}}^{\prime}$ via alkynyl complex. For different energy terms, refer to computational details.

\begin{tabular}{lccccccccc}
\hline Steps & $\Delta E_{\mathrm{e}}$ & $\Delta H_{298}$ & $\Delta G_{298}$ & $\Delta E_{\mathrm{L}}^{\mathrm{S}}$ & Steps & $\Delta E_{\mathrm{e}}$ & $\Delta H_{298}$ & $\Delta G_{298}$ & $\Delta E_{\mathrm{L}}^{S}$ \\
\hline $\mathbf{3}_{\mathbf{a}}^{\prime} \rightarrow\left[\mathbf{3}_{\mathbf{a}}^{\prime}-\mathbf{6}_{\mathbf{a}}^{\prime}\right]^{\ddagger}$ & 8.0 & 7.3 & 8.5 & 12.6 & $\mathbf{3}_{\mathbf{d}}^{\prime} \rightarrow\left[\mathbf{3}_{\mathbf{d}}^{\prime}-\mathbf{6}_{\mathbf{d}}^{\prime}\right]^{\ddagger}$ & 8.0 & 5.0 & 7.6 & 6.9 \\
{$\left[\mathbf{3}_{\mathbf{a}}^{\prime}-\mathbf{6}_{\mathbf{a}}^{\prime}\right]^{+} \rightarrow \mathbf{6}_{\mathbf{a}}^{\prime}$} & -3.9 & -2.7 & -6.8 & -6.7 & {$\left[\mathbf{3}_{\mathbf{d}}^{\prime}-\mathbf{6}_{\mathbf{d}}^{+} \mathbf{6}_{\mathbf{d}}^{\prime} \rightarrow \mathbf{6}_{\mathbf{d}}^{\prime}\right.$} & -0.9 & 4.2 & -1.2 & -0.2 \\
$\mathbf{6}_{\mathbf{a}}^{\prime} \rightarrow \mathbf{7}_{\mathbf{a}}^{\prime}$ & 90.7 & 89.7 & 92.6 & 41.8 & $\mathbf{6}_{\mathbf{d}}^{\prime} \rightarrow \mathbf{7}_{\mathbf{d}}^{\prime}$ & 94.1 & 88.9 & 91.3 & 45.5 \\
\hline
\end{tabular}
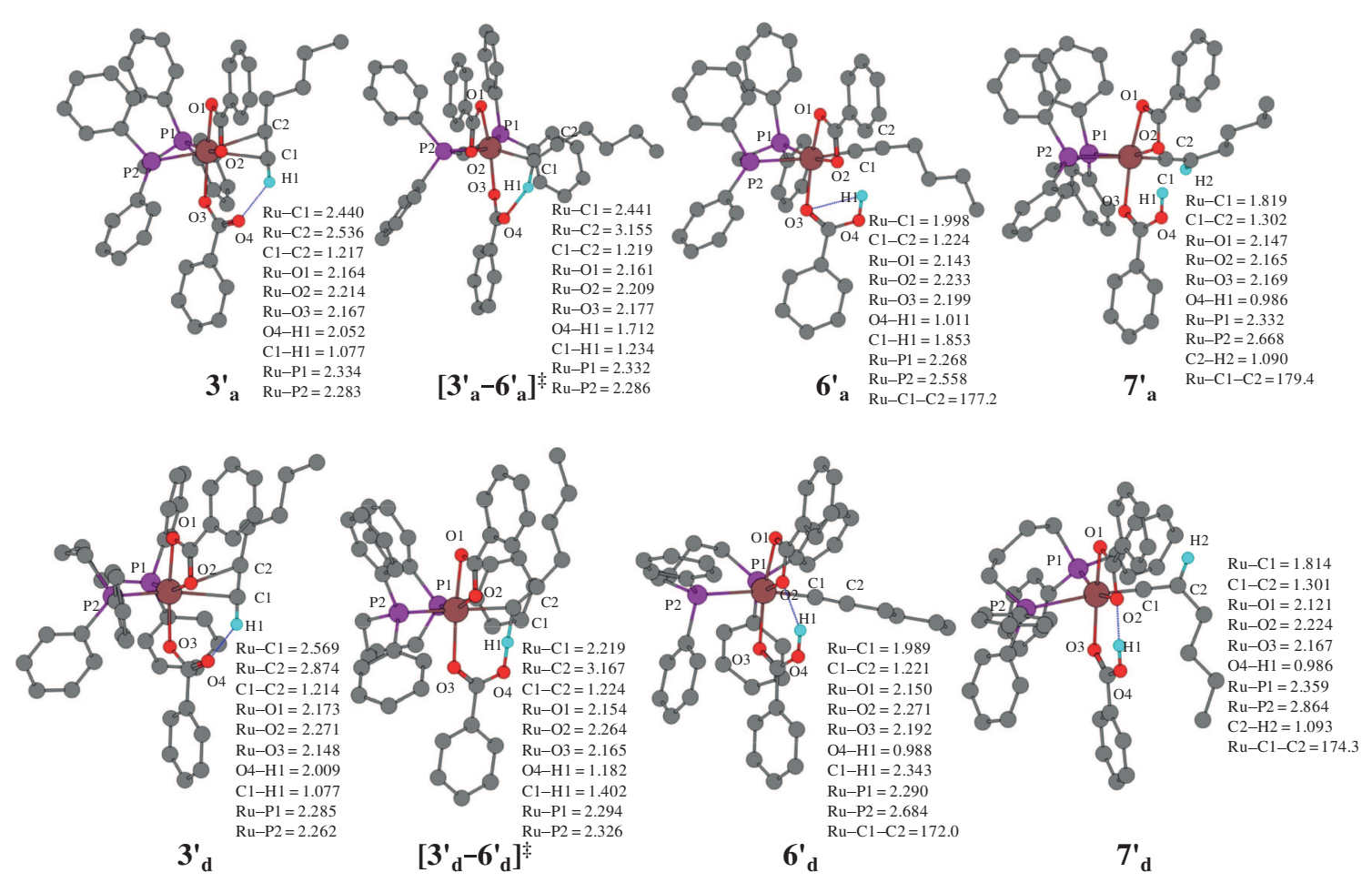

Figure 3. Optimized geometries of intermediates and transition states involved in cationic vinylidene formation step. For other conventions, refer to figure 1. 
of neutral ruthenium(II)-vinylidene intermediates while explaining the mechanism for hydroamidation reaction of terminal alkynes under toluene medium. ${ }^{26}$

3.2c Nucleophilic attack step to vinylidene: It has been reported in experimental studies that in presence of catalyst [(bis(diphenylphosphino)butane) $\mathrm{Ru}\left(\eta^{2}\right.$ $\left.\mathrm{O}_{2} \mathrm{CCF}_{3}\right)_{2}$ ], the trifluoroacetate group does not add to the 1-hexyne, ruling out any internal attack of nucleophile on either $\mathbf{3}_{\mathbf{x}}$ or $\mathbf{5}_{\mathbf{x}}$ intermediates. We have discussed the formation of two types of vinylidenes intermediates: neutral $\left(\mathbf{5}_{\mathbf{a} / \mathbf{d}}\right)$ and cationic $\left(\mathbf{7}_{\mathbf{a} / \mathbf{d}}^{\prime}\right)$. However, the calculated results suggest the formation of cationic vinylidenes to be highly endergonic and hence require no further discussion. From the comparative energy values shown in schemes 4 and 5 , it is necessary to understand that for reactions emanating from catalyst $\mathbf{1}_{\mathrm{a}}$, the Markovnikov addition is energetically more favourable than anti-Markovnikov product formation (vide infra). Therefore, the pathway following the neutral vinylidene intermediate $\mathbf{5}_{\mathbf{a}}$ will be least feasible in this case. Whereas, for catalyst $\mathbf{1}_{\mathbf{d}}$, the neutral vinylidene pathway reveals lower energy barriers than the Markovnikov addition route (red lines, figure $5 b$ ). Similar to typical vinylidenes, the $\mathrm{C} 1$ atom in $\mathbf{5}_{\mathbf{d}}$ is highly positive $\left(q_{\mathrm{C} 1}=0.427 e\right)$ luring the nucleophile to attack. The LUMO in $\mathbf{5}_{\mathbf{d}}$ is the $\mathrm{p}_{x}$ atomic orbital of $\mathrm{C} 1$ residing on the $x y$ plane containing the $\mathrm{C} 1-\mathrm{C} 2-\mathrm{H}-\mathrm{Bu}$ fragment (figure S3). Therefore, there exists two possibilities for benzoic acid to coordinate the $\mathrm{C} 1$ center; either syn- or anti- with respect to the butyl fragment giving rise to $E$ - or $Z$-enol esters (III or II, respectively). The approach of benzoic acid from two different sides allowed the formation of pre-complexes $\mathbf{8}_{\mathbf{d}}-\mathbf{E}$ and $\mathbf{8}_{\mathbf{d}}-\mathbf{Z}$ (scheme 8, figure 4), which are common in gas-phase mechanistic studies. ${ }^{27}$ The proximity of $\mathrm{O} 1$ and $\mathrm{O} 4$ the acidic hydrogen of benzoic acid in intermediates $\mathbf{8}_{\mathbf{d}}-\mathbf{E}$ and $\mathbf{8}_{\mathbf{d}}-\mathbf{Z}$, enhances the nucleophilicity of the acid oxygen facilitating smooth attack to the $\mathrm{C} 1$ center. The activation barriers for the nucleophilic attack steps are relatively low: $12.4,6.4 \mathrm{kcal} / \mathrm{mol}$ (refer to table 6) for the steps $\mathbf{8}_{\mathbf{d}}-\mathbf{E}$ $\rightarrow \mathbf{9}_{\mathbf{d}}-\mathbf{E}$ and $\mathbf{8}_{\mathrm{d}}-\mathbf{Z} \rightarrow \mathbf{9}_{\mathrm{d}}-\mathbf{Z}$. The activated complexes $\left[\mathbf{8}_{\mathbf{d}}-\mathbf{9}_{\mathbf{d}}-\mathbf{E}\right]^{\ddagger}$ and $\left[\mathbf{8}_{\mathbf{d}}-\mathbf{9}_{\mathbf{d}}-\mathbf{Z}\right]^{\ddagger}$ are characterized with a single negative eigenmode depicting the movement of oxygen towards the $\mathrm{C} 1$ with concomitant hydrogen transfer to $\mathrm{O} 1 / \mathrm{O} 4$. The activation barrier in case of the $Z$-attack is lower than the $E$-attack due to a larger steric congestion of the phenyl rings of P1 atoms towards the incoming benzoic acid group. The final intermediates $\mathbf{9}_{\mathbf{d}}-\mathbf{E}$ and $\mathbf{9}_{\mathbf{d}}-\mathbf{Z}$ will eventually undergo reductive elimination to furnish respective $E$ - and $Z$-products along with regeneration of the catalyst $\mathbf{2}_{\mathrm{d}}$.

\subsection{Regio- and stereo-selectivity}

Comparison of both regio- and stereo-selective additions of benzoic acid to 1-hexyne in presence of two sets of catalyst is schematically captured in the comparative energetics $\left(\Delta G_{\mathrm{L}}^{S}\right)$ plot shown in figure 5. It is evident from the calculated energy profiles that pathways tracing the cationic vinylidenes $\left(7_{\mathbf{a} / \mathbf{d}}^{\prime}\right.$; dotted black line) are highly endothermic and hence will not be followed in the present case. On the left side are the two competing pathways: the Markovnikov addition from $\mathbf{3}_{\mathrm{a} / \mathbf{d}}$ (thick red line) and anti-Markovnikov addition via neutral vinylidene $\mathbf{5}_{\mathbf{a} / \mathbf{d}}$ (thin blue line). For catalyst $\mathbf{1}_{\mathbf{a}}$, Markovnikov

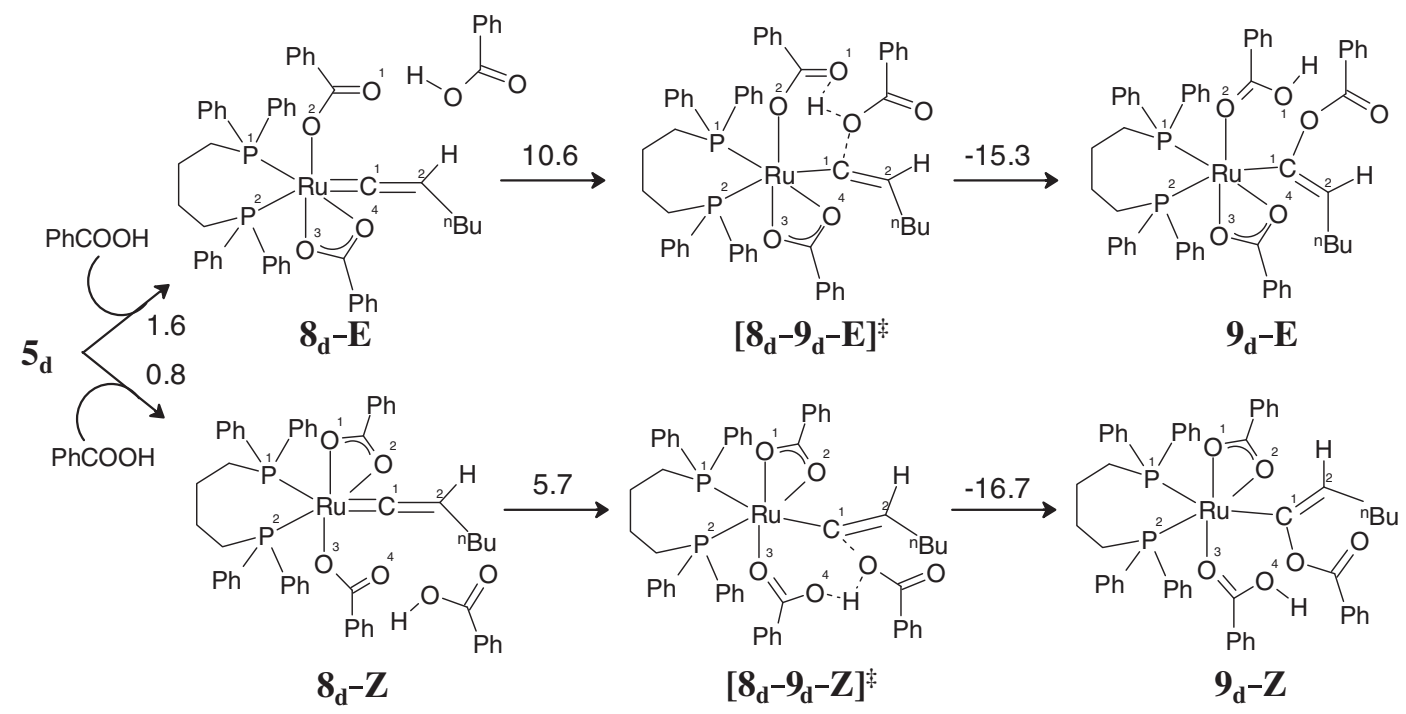

Scheme 8. Nucleophilic attack step to the vinylidene intermediate $\mathbf{5}_{\mathbf{d}}$. For energy conventions, see scheme 2. 


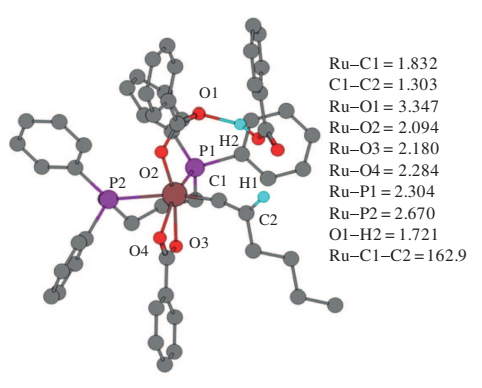

$\mathbf{8}_{\mathrm{d}}-\mathbf{E}$

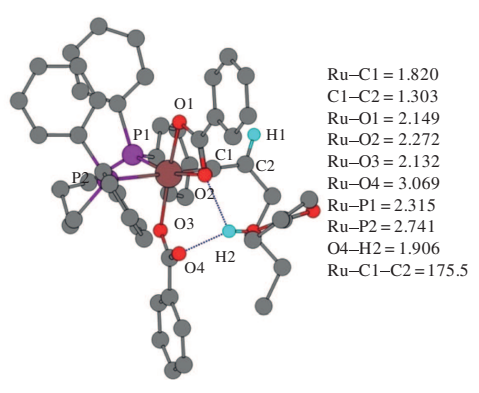

$\mathbf{8}_{\mathbf{d}}-\mathbf{Z}$

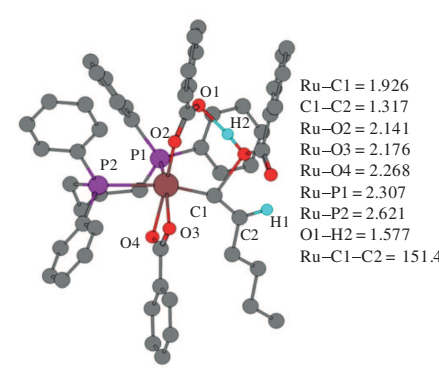

$\left[8_{d}-9_{d}-\mathbf{E}\right]^{*}$

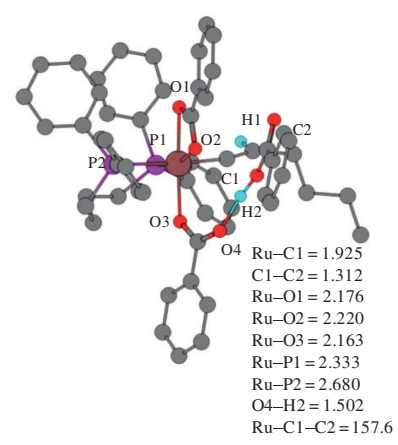

$\left[8_{d}-9-Z\right]^{*}$

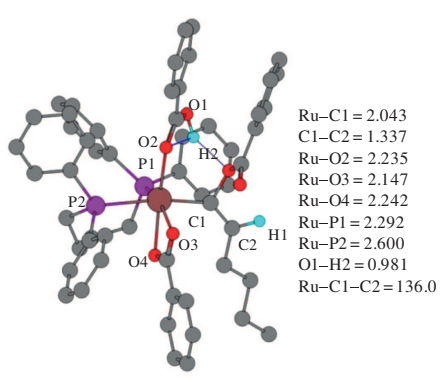

$9 \mathrm{~d}-\mathbf{E}$

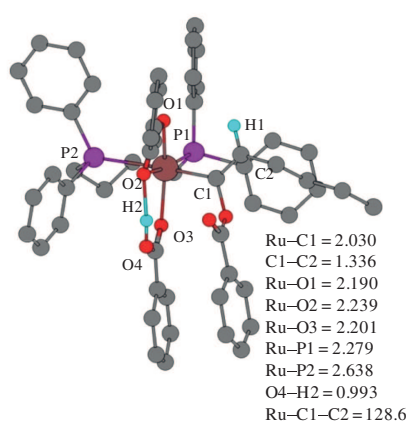

$\mathbf{9}_{\mathrm{d}}-\mathbf{Z}$

Figure 4. Optimized geometries of intermediates and transition states involved in nucleophilic attack step for the vinylidene intermediate $\mathbf{5}_{\mathbf{d}}$. For other conventions, refer to figure 1 .

Table 6. Energy changes (in $\mathrm{kcal} / \mathrm{mol}$ ) for the step of nucleophilic attack the $\mathbf{5}_{\mathbf{d}}$ intermediate. For different energy terms, refer to computational details.

\begin{tabular}{lccccccccc}
\hline Steps & $\Delta E_{\mathrm{e}}$ & $\Delta H_{298}$ & $\Delta G_{298}$ & $\Delta E_{\mathrm{L}}^{S}$ & Steps & $\Delta E_{\mathrm{e}}$ & $\Delta H_{298}$ & $\Delta G_{298}$ & $\Delta E_{\mathrm{L}}^{S}$ \\
\hline $\mathbf{5}_{\mathbf{d}} \rightarrow \mathbf{8}_{\mathbf{d}}-\mathbf{E}$ & -15.5 & -14.6 & -3.6 & -10.3 & $\mathbf{5}_{\mathbf{d}} \rightarrow \mathbf{8}_{\mathbf{d}}-\mathbf{Z}$ & -19.7 & -19.1 & -6.5 & -12.5 \\
$\mathbf{8}_{\mathbf{d}}-\mathbf{E} \rightarrow\left[\mathbf{8}_{\mathbf{d}}-\mathbf{9}_{\mathbf{d}}-\mathbf{E}\right]^{\ddagger}$ & 6.0 & 4.9 & 8.4 & 8.3 & $\mathbf{8}_{\mathbf{d}}-\mathbf{Z} \rightarrow\left[\mathbf{8}_{\mathbf{d}}-\mathbf{9}_{\mathbf{d}}-\mathbf{Z}\right]^{\ddagger}$ & 4.0 & 2.9 & 2.3 & 7.3 \\
{$\left[\mathbf{8}_{\mathbf{d}}-\mathbf{9}_{\mathbf{d}}-\mathbf{E}\right]^{\ddagger} \rightarrow \mathbf{9}_{\mathbf{d}}-\mathbf{E}$} & -19.9 & -17.8 & -18.5 & -16.8 & {$\left[\mathbf{8}_{\mathbf{d}}-\mathbf{9}_{\mathbf{d}}-\mathbf{Z}\right]^{\ddagger} \rightarrow \mathbf{9}_{\mathbf{d}}-\mathbf{Z}$} & -25.4 & -23.0 & -22.4 & -19.6 \\
\hline
\end{tabular}
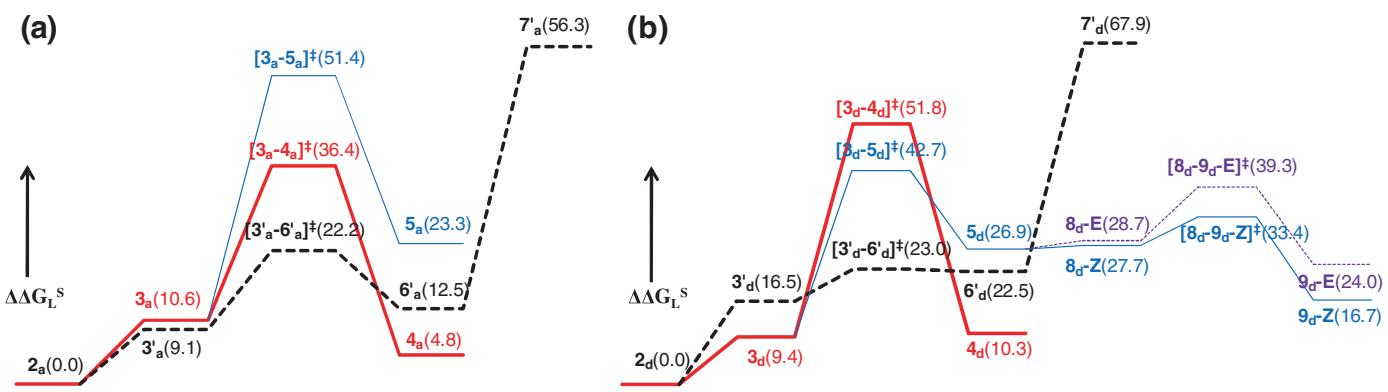

Figure 5. Energetics of different pathways for catalysts $\mathbf{1}_{\mathbf{a}}(\mathbf{a})$ and $\mathbf{1}_{\mathbf{d}}(\mathbf{b})$. Colour code: thick (red) lines for Markovnikov, thin (blue) lines for anti-Markovnikov via neutral vinylidenes and dotted (black) lines for anti-Markovnikov via cationic vinylidenes.

addition pathway is most preferred; while for $\mathbf{1}_{\mathbf{d}}$, the anti-Markovnikov addition remains favourable. The results are in good agreement with the experimental observations reported so far. Closer inspection of the reaction profile reveals that the relative energy difference between the Markovnikov and anti-Markovnikov barriers in case of catalyst $\mathbf{1}_{\mathbf{d}}$ is lower than in
$\mathbf{1}_{\mathbf{a}}\left(\Delta \Delta^{\ddagger} G_{\mathrm{L}}^{S}\left(\mathbf{1}_{\mathbf{a}} / \mathbf{1}_{\mathbf{d}}=15.0 / 9.1 \mathrm{kcal} / \mathrm{mol}\right.\right.$; figure 5). So, we can infer that under elevated reaction temperatures, product mixtures containing both the regio-selective enol esters can be detected for catalyst $\mathbf{1}_{\mathbf{d}}$. Satisfyingly, the experimental results show a substantial increase in Markovnikov product formation using catalyst $\mathbf{1}_{\mathbf{d}}$ under reaction temperature of $373 \mathrm{~K}$. Furthermore, in case of 
$\mathbf{1}_{\mathbf{d}}$, the calculated results show a clear preference for $Z$-selective enol esters (II) as an outcome of the antiMarkovnikov addition process (blue line for $Z$ - and purple dotted line for $E$-product in figure 5 b), supporting the experimental finding reported by Dixneuf et al.

\section{Conclusions}

In the present DFT study, we have addressed the role of chelating phosphine ligands in governing the regioselectivity of ruthenium(II)-catalysed benzoic acid addition to 1-hexyne. For general catalyst system of the type: $\left[\left(\mathrm{Ph}_{2} \mathrm{P}\left(\mathrm{CH}_{2}\right)_{\mathrm{m}} \mathrm{PPh}_{2}\right) \mathrm{Ru}(\text { methallyl })_{2}\right]$, modifying the length of the spacer $\left(\mathrm{CH}_{2}\right)_{\mathrm{m}}$ unit resulted in different regio-controlled enol ester products. Reactions performed using catalyst $\mathbf{1}_{\mathbf{a}}\left[\left(\mathrm{Ph}_{2} \mathrm{P}\left(\mathrm{CH}_{2}\right)\right.\right.$ $\mathrm{PPh}_{2} \mathrm{Ru}$ (methallyl $\left.)_{2}\right]$, where $m=1$, the Markovnikov added product (I) was obtained as major quantity. In case of catalyst $\mathbf{1}_{\mathbf{d}}\left[\left(\mathrm{Ph}_{2} \mathrm{P}\left(\mathrm{CH}_{2}\right)_{4} \mathrm{PPh}_{2} \mathrm{Ru}(\text { methallyl })_{2}\right]\right.$ the anti-Markovnikov addition product was predominant. In the presence of $\mathbf{1}_{\mathbf{a}}$, the calculated energy values show the Markovnikov addition pathway to be more favourable by $15.0 \mathrm{kcal} / \mathrm{mol}$. In contrast, for $\mathbf{1}_{\mathrm{d}}$, the anti-Markovnikov addition leading to the $Z$ enol ester (II) was more favourable than the other regio-selective pathway by $9.1 \mathrm{kcal} / \mathrm{mol}$. In order to obtain II, addition of benzoic acid to the $\mathrm{C} 1$ centres of $\left[\left(\mathrm{Ph}_{2} \mathrm{P}\left(\mathrm{CH}_{2}\right)_{1 / 4} \mathrm{PPh}_{2} \mathrm{Ru}\left(\eta^{2}-\mathrm{O}_{2} \mathrm{CPh}\right)_{2}\left(\eta^{2}\right.\right.\right.$-hexyne $\left.)\right]\left(\mathbf{3}_{\mathrm{a} / \mathbf{d}}\right)$ is necessary. However, sufficient electron density at the $\mathrm{C} 1$ centre refrains the occurrence of coordination. Hence, alternative pathways for anti-Markovnikov addition accompanying the vinylidene intermediates are considered. We have shown pathways following both neutral as well as cationic vinylidene complexes. Formation of cationic vinylidenes demands very high energy and are hence not considered as a preferred reaction route. Pathways leading through neutral vinylidenes are more realistic in terms of energy values, particularly the addition of benzoic acid to $\left[\left(\mathrm{Ph}_{2} \mathrm{P}\left(\mathrm{CH}_{2}\right)_{4} \mathrm{PPh}_{2} \mathrm{Ru}\left(\mathrm{O}_{2} \mathrm{CPh}\right)_{2}(=\mathrm{C}=\mathrm{CHBu})\right]\left(\mathbf{5}_{\mathbf{d}}\right)\right.$. The activation barrier for the $Z$-enol ester product formation is less than its other stereo-isomers (III) by 5.9 $\mathrm{kcal} / \mathrm{mol}$. The difference in energy arises from the steric interaction of the phenyl groups coordinated to the phosphorus atom with the incoming benzoic acid during the anti-attack. The calculated results are in good agreement with the experimental findings from the group of Doucet and Dixneuf. Moreover, considering our calculated NPA charges at the $\mathrm{C} 2$ atoms in intermediates $\mathbf{3}_{\mathrm{x}}$, we can correctly predict the formation of the Markovnikov addition product if at all possible. Our calculated results provide good interpretation of the role of ancillary chelating phosphine ligands in controlling the regio-selectivity of benzoic acid as reported in the experimental observations. Further mechanistic investigations by our group are in progress.

\section{Supplementary Information}

Steric effect in ligand exchange step $\left(\mathbf{1}_{\mathbf{x}} \rightarrow \mathbf{2}_{\mathbf{x}}\right)$ and related optimized geometries are given in scheme $\mathrm{S} 1$ and figure S1. Figure S2 represents the oxidative addition in $\mathbf{3}_{\mathbf{d}}$ intermediate. KS-LUMO of $\mathbf{5}_{\mathbf{d}}$ and nucleophilic approach of that intermediate are shown in figure S2. Absolute total energy (in Hartrees) and Cartesian coordinates of all intermediates and transition states are shown in tables S1 and S2, respectively. For details see www.ias.ac.in/chemsci website.

\section{Acknowledgement}

The authors are thankful to IISER-Kolkata for providing computational facility. BM and TM are thankful to CSIR for their respective SRF and JRF fellowships. KD and SB gratefully acknowledge INSPIRE, DST. DK acknowledges IISER-Kolkata for start-up grant and SERB for DST fast track fellowship (SR/FT/SC72/2011).

\section{References}

1. (a) Rozen S and Lerman O 1979 J. Am. Chem. Soc. 101 2782; (b) Wexler A, Balchunis R J and Swenton J S 1975 J. Chem. Soc., Chem. Commun. 15 601; (c) House H O 1972 Modern synthetic reactions, $2^{\text {nd }}$ edn Menlo Park, CA: W A Benjamin 313. (d) Tsuji J, Minami I and Shimizu I 1983 Tetrahedron Lett. 24 4713; (e) Schmitt G Warwel S, Homminga E and Meltzow W 1972 Justus Liebigs Ann. Chem. 76375

2. (a) Monthéard J P, Camps M, Seytre G, Guillet J and Dubois J C 1978 Angew. Makromol. Chem. 72 45; (b) Seidel A, Jägers E and Bylsma F 1993 Eur. Pat. 0574 $725 \mathrm{~A} 1$

3. Rotem M and Shvo Y 1983 Organometallics 21689

4. (a) Mitsudo T, Hori Y and Watanabe Y 1985 J. Org. Chem. 501566 (b) Mitsudo T, Hori Y, Yamakawa Y and Watanabe Y 1987 J. Org. Chem. 522230

5. (a) Doucet H, Hofer J, Bruneau C and Dixneuf P H 1993 J. Chem. Soc., Chem. Commun. 10850 (b) Doucet H, Martin-Vanca B, Bruneau C and Dixneuf P H 1995 J. Org. Chem. 607247 (c) Doucet P, Derrien N, Kabouche Z, Bruneau C and Dixneuf P H 1997 J. Organomet. Chem. 551151 (d) Bruneau C and Dixneuf P H 1999 Acc. Chem. Res. 32311 and references therein

6. Bruneau C, Neveux-Duflos M and Dixneuf P H 1999 Green Chem. 1183

7. Goossen L J, Paetzold J and Koley D 2003 Chem. Commun. 6706 
8. (a) Bruneau C and Dixneuf P H 2008 Angew. Chem. Int. Ed. 478492 (b) Rigaut S, Touchard D and Dixneuf P H 2004 Coord. Chem. Rev. 2481585

9. Gaussian 09, Revision C.01, Frisch M J, Trucks G W, Schlegel H B, Scuseria G E, Robb M A, Cheeseman J R, Scalmani G, Barone V, Mennucci B, Petersson G A, Nakatsuji H, Caricato M, Li X, Hratchian H P, Izmaylov A F, Bloino J, Zheng G, Sonnenberg J L, Hada M, Ehara M, Toyota K, Fukuda R, Hasegawa J, Ishida M, Nakajima T, Honda Y, Kitao O, Nakai H, Vreven, T, Montgomery Jr J A, Peralta J E, Ogliaro F, Bearpark M, Heyd J J, Brothers E, Kudin K N, Staroverov V N, Kobayashi R, Normand J, Raghavachari K, Rendell A, Burant J C, Iyengar S S, Tomasi J, Cossi M, Rega N, Millam J M, Klene M, Knox J E, Cross J B, Bakken V, Adamo C, Jaramillo J, Gomperts R, Stratmann R E, Yazyev O, Austin A J, Cammi R, Pomelli C, Ochterski J W, Martin R L, Morokuma K, Zakrzewski V G, Voth G A, Salvador P, Dannenberg J J, Dapprich, S, Daniels A D, Farkas Ö, Foresman J B, Ortiz J V, Cioslowski J and Fox D J Gaussian, Inc., Wallingford CT, 2010

10. (a) Maseras F and Morokuma K 1995 J. Comput. Chem. 161170 (b) Vrevenand T and Morokuma K $2000 \mathrm{~J}$. Comput.Chem. 211419

11. (a) Hay P J and Wadt W 1985 J. Chem. Phys. 82270 (b) Hay P J, and Wadt W 1985 J. Chem. Phys. 82284 (c) Hay P J and Wadt W 1985 J. Chem. Phys. 82299

12. Hehre W J, Radom L, Schleyer P v R and Pople J A 1986 Ab initio molecular orbital theory (New York: Wiley)

13. Helgren T A and Lipscomb W N 1977 Chem. Phys. Lett. 49225

14. Marenich A V, Cramer C J and Truhlar D 2009 J. Phys. Chem. B 1136378
15. Reed A E, Curtiss L A and Weinhold F 1998 Chem. Rev. 88899

16. (a) Oliván M, Eisenstein O and Caulton K G 1997 Organometallics 162227 (b) Oliván M, Clot E, Eisenstein O and Caulton K G 1998 Organometallics 17 3091

17. Kostic N M and Fenske R F 1982 Organometallics 1 974

18. Bruneau C and Dixneuf P H 2006 Angew. Chem. 118 2232; Angew. Chem. Int. Ed. 452176

19. Varela-Fernández A, González-Rodríguez C, Varela J A, Castedo L and Saá C 2009 Org. Lett. 115350

20. Wakatsuki Y, Koga N, Yamazaki H and Morokuma K 1994 J. Am. Chem. Soc. 1168105

21. Tokunaga M, Suzuki T, Koga N, Fukushima T, Horiuchi A and Wakatsuki Y 2001 J. Am. Chem. Soc. 12311917

22. (a) Höhn A, Otto H, Dziallas M and Werner H 1987 J. Chem. Soc., Chem. Commun. 852 (b) Alonso F J G, Höhn A, Wolf J, Otto H and Werner H 1985 Angew. Chem. Int. Ed. 24406

23. Cadierno V, Gamasa M P and Gimeno J 1999 Organometallics $\mathbf{1 8} 2821$

24. Silvestre J and Hoffmann R 1985 Helv. Chim. Acta. 68 1461

25. Arndt M, Salih K S M, Fromm A, Goossen L J, Menges F and Schatteburg G N 2011 J. Am. Chem. Soc. 133 7428

26. (a) Gooßen L J, Koley D, Hermann H L and Thiel W 2004 Chem. Commun. 192141 (b) Goossen L J, Koley D, Hermann H L and Thiel W 2005 J. Am. Chem. Soc. 127, 11102

27. Consiglio G, Morandini F, Ciani G F and Sironi A 1986 Organometallics 51976 